\title{
Sensitivity of airborne radio occultation to tropospheric properties over ocean and land
}

\author{
Feiqin Xie $^{1}$, Loknath Adhikari ${ }^{1}$, Jennifer S. Haase ${ }^{2}$, Brian Murphy ${ }^{3, \text { a }}$, Kuo-Nung Wang ${ }^{4}$, and James L. Garrison ${ }^{5}$ \\ ${ }^{1}$ Department of Physical and Environmental Sciences, Texas A\&M University - Corpus Christi, Corpus Christi, Texas, USA \\ ${ }^{2}$ Scripps Institution of Oceanography, University of California, San Diego, California, USA \\ ${ }^{3}$ Department of Earth, Atmospheric, and Planetary Sciences, Purdue University, West Lafayette, Indiana, USA \\ ${ }^{4}$ Jet Propulsion Laboratory, California Institute of Technology, Pasadena, California, USA \\ ${ }^{5}$ School of Aeronautics and Astronautics, Purdue University, West Lafayette, Indiana, USA \\ ${ }^{a}$ now at: Edison State Community College, Piqua, Ohio, USA
}

Correspondence: Feiqin Xie (feiqin.xie@tamucc.edu)

Received: 17 June 2017 - Discussion started: 5 July 2017

Revised: 5 December 2017 - Accepted: 19 December 2017 - Published: 8 February 2018

\begin{abstract}
Airborne radio occultation (ARO) measurements collected during a ferry flight at the end of the PREDepression Investigation of Cloud-systems in the Tropics (PREDICT) field campaign from the Virgin Islands to Colorado are analyzed. The large contrast in atmospheric conditions along the flight path from the warm and moist Caribbean Sea to the much drier and cooler continental conditions provides a unique opportunity to address the sensitivity of ARO measurements to the tropospheric temperature and moisture changes. This long flight at nearly constant altitude $(\sim 13 \mathrm{~km})$ provided an optimal configuration for simultaneous high-quality ARO measurements from two high-gain side-looking antennas, as well as one relatively lower gain zenith (top) antenna. The omnidirectional top antenna has the advantage of tracking robustly more occulting satellites in all direction as compared to the limited-azimuth tracking of the side-looking antennas. Two well-adapted radioholographic bending angle retrieval methods, full-spectrum inversion (FSI) and phase matching (PM), were compared with the standard geometric-optics (GO) retrieval method. Comparison of the ARO retrievals from the top antenna with the near-coincident ECMWF reanalysis-interim (ERAI) profiles shows only a small root-mean-square (RMS) refractivity difference of $\sim 0.3 \%$ in the drier upper troposphere from $\sim 5$ to $\sim 11.5 \mathrm{~km}$ over both land and ocean. Both the FSI and PM methods improve the ARO retrievals in the moist lower troposphere and reduce the negative bias found in the GO retrieval due to atmospheric multipath. In the lowest
\end{abstract}

layer of the troposphere, the ARO refractivity derived using FSI shows a negative bias of about $-2 \%$. The increase of the refractivity bias occurs below $5 \mathrm{~km}$ over the ocean and below $3.5 \mathrm{~km}$ over land, corresponding to the approximate altitude of large vertical moisture gradients above the ocean and land surface, respectively. In comparisons to radiosondes, the FSI ARO soundings capture well the height of layers with sharp refractivity gradients but display a negative refractivity bias inside the boundary layer. The unique opportunity to make simultaneous independent recordings of occultation events from multiple antennas establishes that high-precision ARO measurements can be achieved corresponding to an RMS difference better than $0.2 \%$ in refractivity (or $\sim 0.4 \mathrm{~K}$ ). The surprisingly good quality of recordings from a very simple zenith antenna increases the feasibility of developing an operational tropospheric sounding system onboard commercial aircraft in the future, which could provide a large number of data for direct assimilation in numerical weather prediction models.

\section{Introduction}

Radio signals from global navigation satellite systems (GNSSs) can be used to sense the atmosphere during a radio occultation (RO) event, when the GNSS signals traverse progressively lower (or higher) atmospheric layers as a moving receiver sets behind (or rises above) the Earth's limb 
(e.g., Kursinski et al., 1997; Rocken et al., 1997). Numerous low Earth orbit (LEO) satellites equipped with GNSS RO receivers have been launched since the first Global Positioning System (GPS) RO mission, the GPS/Met in 1995 (Ware et al., 1996). The spaceborne GNSS RO measurements provide high-vertical-resolution all-weather atmospheric soundings, which complement the conventional passive infrared and microwave sounders with their relatively low vertical resolution and high horizontal resolution, and greatly contribute to global weather forecasting. In 2006, the launch of the six-satellite Constellation Observing System for Meteorology, Ionosphere, and Climate (COSMIC) and the GNSS Receiver for Atmospheric Sounding (GRAS) onboard MetOp began producing about 3000 daily soundings globally (Anthes et al., 2008; Luntama et al., 2008). The RO soundings were operationally assimilated into the numerical weather prediction (NWP) models at many leading weather centers and demonstrated significant impact in the upper troposphere and lower stratosphere (UTLS) (e.g., Healy and Thépaut, 2006; Cucurull and Derber, 2008). The spaceborne RO measurements have advanced knowledge of various physical processes, including the troposphere-stratosphere exchange, gravity waves, hurricane/typhoon evolution, and planetary boundary layer (see Anthes, 2011, and references therein). However, there is relatively limited impact of RO measurements in the lower troposphere, especially on mesoscale phenomena such as severe storm forecasting and small scale processes within tropical storms. The low temporal and spatial sampling rate of spaceborne $\mathrm{RO}$ soundings at the regional scale (e.g., only $\sim 1$ daily profile over $400 \mathrm{~km} \times 400 \mathrm{~km}$ area) typically cannot capture the variation of atmospheric moisture and temperature during the lifetime of mesoscale weather phenomena. In addition, RO refractivity biases seen in the lower troposphere due to uncertainty in signal tracking (e.g., Ao et al., 2003, 2009; Beyerle et al., 2006; Sokolovsky et al., 2010) and the presence of ducting (e.g., Sokolovsky, 2003; Xie et al., 2006, 2010; Ao et al., 2007) lead to degraded RO retrievals and reduced impact. The upcoming COSMICII mission could double or triple the number of RO soundings but would still offer a limited number of observations over mesoscale and transient weather events.

In contrast, using GNSS receivers onboard an aircraft, dense airborne RO soundings can be collected over the target region during mesoscale and transient weather events. For a receiver within the atmosphere, the airborne RO (ARO) technique differs from the spaceborne technique (Zuffada et al., 1999; Healy et al., 2002; Xie et al., 2008) in that the raypath through the neutral atmosphere is not symmetric with respect to the tangent point (the point on a ray closest approach to the Earth center). In addition, the nonzero atmospheric refractivity at the receiver cannot be neglected. Therefore, the RO signals from below the local horizon (i.e., negative elevation angle) must be corrected for the delay due to propagation of the signals from the aircraft altitude to the GNSS satellite above the local horizon (i.e., positive elevation angle) to re- trieve atmospheric properties below the receiver (e.g., Healy et al., 2002). After the precise positions of the GNSS satellite and the receiver are known, the excess phase delay due to the atmospheric refraction can be derived by calculating the difference between the measured phase and the GNSSreceiver line-of-sight (LOS) distance. The ARO signal phase and amplitude can then be inverted to derive the atmospheric bending angle, which can be further converted to refractivity through a modified inverse Abel transformation (Healy et al., 2002; Lesne et al., 2002; Xie et al., 2008).

Early field experiments demonstrated the ARO technique by using a conventional closed-loop-tracking ARO receiver flying at a relative low altitude of $\sim 3 \mathrm{~km}$. An exploratory flight system was tested (Yoshihara et al., 2006) but only qualitative conclusions about the performance were drawn. Xie et al. (2008) developed an end-to-end ARO simulation system based on geometric optics to describe in detail the approach, and quantified several key factors affecting the accuracy of the ARO retrievals including the aircraft velocity, in situ refractivity measurement, and the atmospheric horizontal gradient. The GNSS Instrument System for Multistatic and Occultation Sensing (GISMOS) was developed for ARO sounding and reflection measurements (Garrison et al., 2007; Voo et al., 2009). GISMOS was tested in 2008 using the National Science Foundation (NSF) Gulfstream V (GV) research aircraft at flight altitudes of approximately $14 \mathrm{~km}$ over the southeastern United States (Lulich et al., 2010; Muradyan, 2009, 2012). Equipped with a dual frequency conventional GPS receiver and inertial measurement unit, GISMOS provides accurate aircraft position and velocity measurements (less than $5 \mathrm{~mm} \mathrm{~s}^{-1}$ ) which are required for precise ARO retrieval in the lower troposphere (Muradyan et al., 2010). Haase et al. (2014) reported the first results of the ARO measurement and retrievals from the 2010 PRE-Depression Investigation of Cloud-systems in the Tropics (PREDICT) field campaign over the equatorial Atlantic Ocean (Montgomery et al., 2012). Murphy et al. (2015) presented an assessment of the accuracy of ARO bending and refractivity retrievals from the PREDICT field campaign using data from the GISMOS conventional geodetic quality GPS receivers that applied phase-locked loop tracking. The implementation of open-loop tracking on the ARO receiver allows high-quality ARO signal tracking deep into the moist lower troposphere where complicated signal dynamics lead to failed signal tracking by the conventional closed-loop tracking receiver (Wang et al., 2016). This multi-path problem caused by the large moisture variation in the lower troposphere leads to significant bias in ARO retrievals based on the geometric-optics (GO) method. With the successful development and implementation of the radio-holographic retrieval algorithms, including the full spectrum inversion (FSI; Adhikari et al., 2016) and the phase matching (PM; Wang et al., 2017), ARO retrieval quality has been significantly improved in the moist lower troposphere. 
ARO simulation studies (e.g., Lesne et al., 2002; Xie et al., 2008) and previous field observations (Murphy et al., 2015) have demonstrated the large impact of aircraft flight geometry (e.g., altitude, direction) on the ARO sounding density and quality. Due to the much slower motion of the aircraft $\left(\sim 0.25 \mathrm{~km} \mathrm{~s}^{-1}\right)$ compared to LEO satellite $\left(\sim 7 \mathrm{~km} \mathrm{~s}^{-1}\right)$, it generally takes over $20 \mathrm{~min}$ for an ARO receiver to record the required data from the aircraft cruise altitude (e.g., $\sim 10 \mathrm{~km}$ ) down to the surface, which is much longer than a typical spaceborne RO event (1-2 min). In addition, the tangent points during an ARO event also drift much farther $(200-300 \mathrm{~km})$ than a spaceborne RO event (generally less than $\sim 100 \mathrm{~km}$ ). During the research flights from the PREDICT field campaign, the aircraft flew at an average altitude of $\sim 14 \mathrm{~km}$ in "lawnmower" or square spiral patterns over the central region of deep convection associated with tropical disturbances (Haase et al., 2014). The ARO signals were simultaneously recorded from two high-gain antennas mounted on both sides of the aircraft fuselage, and one relatively lower gain zenith antenna on the top of the aircraft (Haase et al., 2014; Murphy et al., 2015; Wang et al., 2016). However, the complicated research flight patterns, i.e., sometimes changing flight direction during an occultation, led to degraded signal tracking from the side-looking antennas as the line of sight deviated from the maximum in the GPS antenna gain pattern (Murphy et al., 2015; Wang et al., 2016).

This study focuses on the ARO measurements collected during a ferry flight at the end of the PREDICT field campaign from the Virgin Islands to Colorado. The large contrast in atmospheric conditions along the flight path from the warm and moist Caribbean Sea to the much drier and cooler continental conditions provides a unique opportunity to address the sensitivity of ARO measurements to the tropospheric temperature and moisture changes. This long flight at nearly constant altitude $(\sim 13 \mathrm{~km})$ provides an optimal configuration for simultaneous high-quality ARO measurements from two side-looking antennas and one top antenna. Such independent recordings of occultation events from multiple antennas allows the evaluation of ARO sounding quality and precision. The quality of the ARO soundings collected from the top antenna are further evaluated by comparing with the near-coincident global reanalysis and radiosonde profiles. In addition, both the well-adapted radio-holographic retrieval methods (FSI and PM) are used and compared with the standard GO retrieval method.

The paper is structured as follows: Sect. 2 describes the GISMOS antenna configuration, and the details of the ARO measurements collected during the ferry flight of the PREDICT campaign. In addition, the independent datasets used to validate the ARO retrievals, including the reanalysis data, and radiosonde soundings are also introduced. Section 3 presents the atmospheric conditions over the study area from reanalysis data. Section 4 evaluates the quality of ARO soundings collected from the top antenna by directly comparing with the reanalysis and radiosonde datasets. The ARO retrieval differences resulting from various ARO retrieval algorithms (GO, FSI, and PM) are also presented. The precision of ARO measurements is also quantified through comparisons among the recordings from the three antennas. Finally, the summary and conclusions are presented in Sect. 5.

\section{Data and methodology}

\subsection{ARO measurement}

The NSF/NCAR Gulfstream V (HIAPER) aircraft, with the GNSS Instrument System for Multistatic and Occultation Sensing (GISMOS) onboard, was deployed in AugustSeptember 2010 for the Pre-Depression Investigation of Cloud systems in the Tropics (PREDICT) field campaign (Montgomery et al., 2012; Haase et al., 2014; Murphy et al., 2015). A total of seven antennas were mounted on the exterior of aircraft including one on the top and two at each side of the fuselage for occultation measurements as well as two on the bottom of the fuselage for GPS reflection measurements (Garrison et al., 2007). During each flight, GISMOS continuously recorded GPS signals at $5 \mathrm{~Hz}$ from geodetic quality dual-frequency Trimble NetRS GPS receivers and simultaneously at $10 \mathrm{MHz}$ using the GNSS Recording System (GRS). In addition to the setting occultation measurements, the GRS doubles the number of ARO soundings by enabling open-loop (OL) tracking technique, which is capable of recording the rising occultation, and allows high-quality signal tracking in the moist lower troposphere (Wang et al., 2016). An Applanix POS/AV ${ }^{\mathrm{TM}}$ inertial navigation system was used to achieve velocity precision better than $5 \mathrm{~mm} \mathrm{~s}^{-1}$ (Muradyan, 2012; Muradyan et al., 2010) as required for airborne retrieval accuracy to be better than $0.5 \%$ in refractivity (Xie et al., 2008).

To evaluate the ARO sounding quality, we focused on the ARO measurements from three antennas, including one omnidirectional avionics antenna mounted on the top of the fuselage (CH1) for precise navigation and high-elevationangle satellite data for clock corrections in addition to occultation measurements, and two high-gain, narrow vertical, and wide azimuthal aperture antennas specially designed for higher sensitivity in tracking low signal-to-noise ratio (SNR) occulting satellites near the horizon, mounted on both the port (right; $\mathrm{CH} 2$ ) and starboard (left; $\mathrm{CH} 3$ ) side of the fuselage (Fig. 1a). In Fig. 1, the azimuth angles are referenced to the antenna boresight direction (i.e., perpendicular to the flight direction in the horizon), with the positive angles measured clockwise (Fig. 1b). Unlike the omnidirectional top antenna with an isotropic azimuthal gain pattern (not shown), the directivity of the side-looking antenna significantly affects the RO signal recording for different observation geometries (Wang et al., 2016). A minimum in the gain pattern exists at $-60^{\circ}$ azimuth (towards the rear of the aircraft, Fig. 1b). In addition, the fuselage will block the RO signal at 
greater than $\pm 90^{\circ}$ azimuth angles. The vertical antenna gain pattern for the side-looking antenna shows relatively uniform gain within $\sim \pm 5^{\circ}$ from the local horizon (Fig. 1c), where the GNSS occultation signals are tracked. The limited horizontal visibility of occulting GNSS satellites from the side-looking antennas results in few high-quality ARO recordings during the research flights with frequent turns (e.g., Murphy et al., 2015). During the ferry flight, however, the relatively constant flight direction and altitude allow high-quality recording from the side-looking antennas.

The GRS samples the wide-band GPS signals at $10 \mathrm{MHz}$ on both L1 and L2 frequencies on all three channels. The wide view angle of the top antenna was found to provide sufficiently high SNR recordings of all ARO occulting satellites that were simultaneously recorded by either the port or starboard antenna. Such simultaneous recording between the top (CH1) and side antennas ( $\mathrm{CH} 2$ or $\mathrm{CH} 3$ ) offers an excellent opportunity to access the precision of the ARO soundings. Note that due to the inconsistencies in the flight level in situ humidity data (Murphy et al., 2015), we used the ECMWF reanalysis data interpolated to the ARO receiver position to compute the refractivity at the receiver rather than the in situ measurements. The sensitivity of the ARO soundings to the accuracy of the in situ refractivity has been examined in previous studies (e.g., Xie et al., 2008; Murphy et al., 2015) and is significant only at heights in the retrieval close to the aircraft altitude.

\subsubsection{Aircraft flight path and ARO soundings}

The HIAPER aircraft was deployed for 26 research flights to studying eight storm systems during the PREDICT field campaign. The aircraft typically flown in a lawnmower or square spiral patterns to allow regular sampling of the development region of the targeted storm system. The quality of ARO soundings collected during the research flights has been analyzed in detail (Murphy et al., 2015). However, the frequent direction and altitude changes during the research flight complicated the ARO signal tracking and led to degraded ARO sounding measurements especially during turns (Murphy et al., 2015; Wang et al., 2016).

After completion of the PREDICT research flights, ARO measurements were then continuously recorded during the return ferry flight from the field station at St. Croix in the US Virgin Islands to the UCAR facility at Broomfield, Colorado, on 2 October 2010. During the ferry flight, the aircraft cruised at a steady altitude of approximately $13 \mathrm{~km}$ above mean sea level (m.s.l.) along a nearly straight flight path, which provided an ideal recording geometry for ARO measurements, especially from the side-looking antennas. Figure 2 shows the aircraft flight path and the tangent points (e.g., local sampling positions) of each recorded occultation. The location of a radiosonde station in Lamont, Oklahoma, near the flight track is also marked. Note that each GPS satellite is named for its unique pseudo-random noise
(PRN) number. Each occultation event is labeled by a pair of PRNs for the occulting GPS satellite and the high-elevation GPS satellite used to correct for the receiver clock errors (e.g., Wang et al., 2016). The ARO tangent point locations were estimated using the geometric-optics ray-tracing method (e.g., Xie et al., 2008) assuming a one-dimensionally varying atmosphere represented by the Climate Impact on Regional Air Quality (CIRA+Q) refractivity climatological model (Kirchengast et al., 1999). It is worth noting that the ARO measurements sample both the moist conditions over the ocean during the early stage of the flight (15:00-16:40 Z) and the relatively dry conditions over land during the final stage of the flight (e.g., 17:00-19:00 Z). In the middle stage of the flight, the ARO senses the coastal region over both land and ocean.

Altogether, a total of $17 \mathrm{ARO}$ events were recorded during the $\sim 4 \mathrm{~h}$ ferry flight (Table 1 ). The wide-view zenith antenna (CH1) recorded all 17 ARO events, whereas the port $(\mathrm{CH} 2)$ and starboard $(\mathrm{CH} 3)$ high-gain antennas recorded 5 and 8 events, respectively. The four missing ARO recording from both side-looking antennas (shaded in Table 1) are due to the low antenna gain at large azimuth angle (over $-60^{\circ}$ ) from the antenna boresight (Fig. 1b). Here the occultation period begins from tracking the occulting satellite at $5^{\circ}$ positive elevation angle above the local horizon until the tangent point descends close to the surface for a setting occultation, and vice versa for a rising occultation. Therefore, the beginning time of each ARO event is defined as when the tangent point (TP) is either at positive elevation angle of $5^{\circ}$ for a setting occultation or near the surface for a rising occultation. Note that the tangent point at zero elevation angle (local horizon) will be at the aircraft altitude. During a setting ARO event, the TPs will gradually descend and move away from the aircraft until the TP touches the surface (Xie et al., 2008), and vice versa for a rising occultation. The TP drift distance measures the distance between the surface projected location of the TP at the aircraft altitude (zero elevation angle) and the TP near the surface at mean sea level. The TP location (latitude and longitude) for each ARO event close to the surface, is also shown. With an aircraft cruising at around $13 \mathrm{~km}$, the average ARO sounding takes about 29 min with the shortest event lasting $\sim 20 \mathrm{~min}$ (prn07-28) and the longest event lasting $\sim 44 \mathrm{~min}$ (prn15-28). Generally, the tangent point drifts away from the aircraft, but will vary in extent with variations in the relative positions and velocities of the occulting GPS satellite and the aircraft. The TP drift distance varies from $181 \mathrm{~km}$ (prn08-19) to $589 \mathrm{~km}$ (prn06-11) with an average of about $375 \mathrm{~km}$. Interestingly the four longest ARO events (i.e., over $33 \mathrm{~min}$ ) actually have relatively short $\mathrm{TP}$ drift distance of less than $300 \mathrm{~km}$.

\subsubsection{ARO retrieval methods}

Similar to the spaceborne RO retrieval, ARO faces the same problems of atmospheric multipath in the GO retrieval 


\section{(a) ARO Antennas on HIAPER}
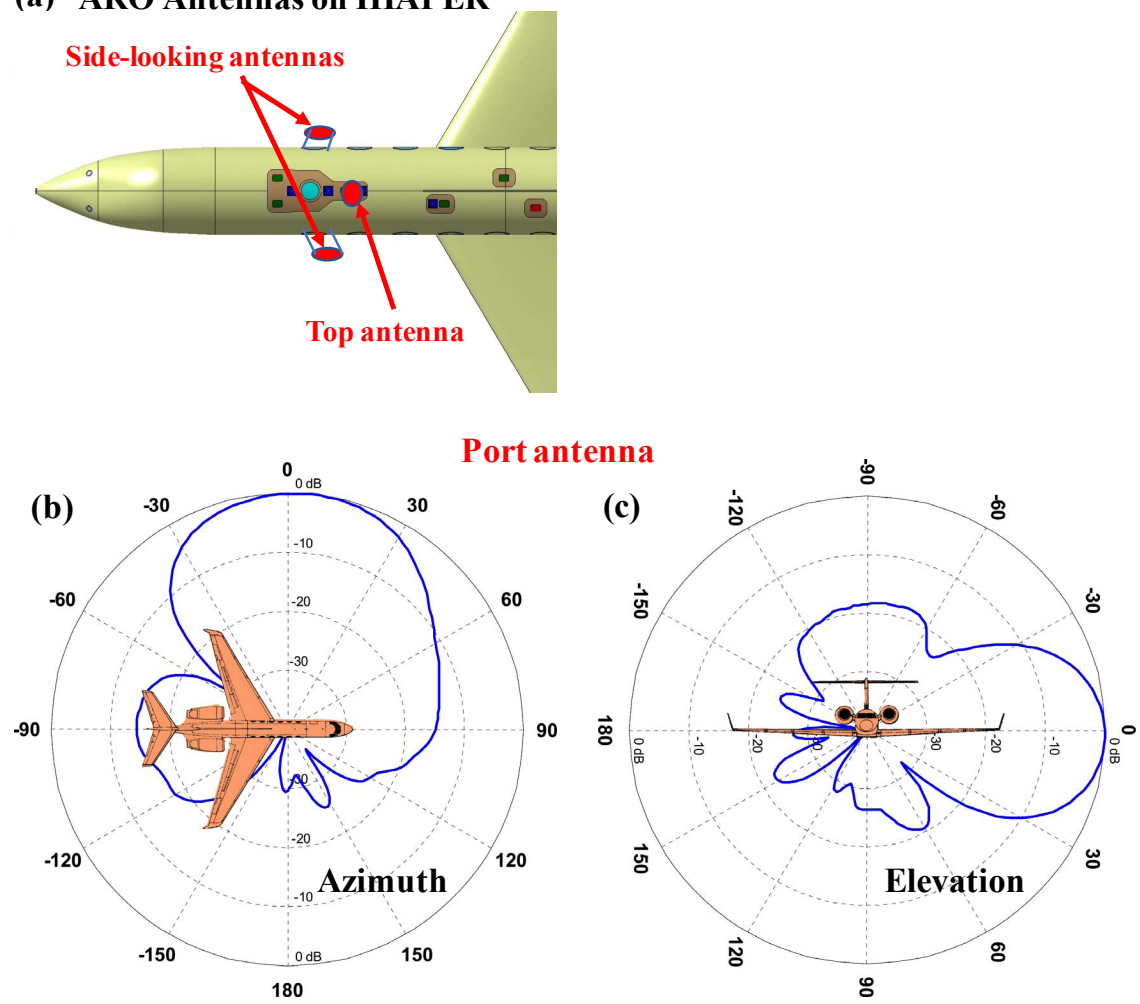

Figure 1. (a) Approximate location of three antennas on the HIAPER aircraft, and (b, c) the port side-looking antenna (CH2) azimuthal and elevation gain pattern, respectively. For the port antenna, $0^{\circ}$ azimuth and elevation are oriented toward the horizon perpendicular to the flight direction (antenna boresight), $90^{\circ}$ in azimuth points forward, and $90^{\circ}$ in elevation points in nadir direction. Note that (b, c) are adapted from Fig. 18 in Wang et al. (2016).

Table 1. List of all ARO events recorded during the ferry flight on 2 October 2010, with the ARO profiles over land shown in bold, and the ARO recording solely from the top antenna $(\mathrm{CH} 1)$ shown in italics.

\begin{tabular}{|c|c|c|c|c|c|c|c|c|}
\hline $\begin{array}{l}\text { prn } \\
\text { no. }\end{array}$ & $\begin{array}{r}\text { Begin time } \\
\text { (UTC hours) }\end{array}$ & $\begin{array}{r}\text { Duration } \\
(\min )\end{array}$ & Channel & $\begin{array}{l}\text { Rising/ } \\
\text { setting }\end{array}$ & $\begin{array}{l}\text { Latitude } \\
\left({ }^{\circ} \mathrm{N}\right)\end{array}$ & $\begin{array}{r}\text { Longitude } \\
\left({ }^{\circ} \mathrm{W}\right)\end{array}$ & $\begin{array}{r}\text { TP drift } \\
(\mathrm{km})\end{array}$ & $\begin{array}{r}\text { Azimuth } \\
\text { (deg) }\end{array}$ \\
\hline prn28-19 & 14.68 & 33.6 & 1 & $R$ & 19.76 & -72.06 & 263 & 62.9 \\
\hline prn08-19 & 14.76 & 24.0 & 1,3 & $\mathrm{R}$ & 23.39 & -71.47 & 181 & 77.4 \\
\hline prn31-19 & 14.83 & 23.4 & 1 & $S$ & 18.95 & -68.19 & 287 & -74.3 \\
\hline prn01-19 & 14.94 & 36.6 & 1,3 & $\mathrm{~S}$ & 23.42 & -69.17 & 291 & -58.1 \\
\hline prn16-19 & 15.72 & 35.4 & 1,3 & $\mathrm{~S}$ & 25.74 & -74.59 & 255 & $-63.8^{*}$ \\
\hline prn17-19 & 15.31 & 27.6 & 1,2 & $\mathrm{R}$ & 19.26 & -75.34 & 504 & 19.7 \\
\hline prn06-11 & 16.12 & 32.4 & 1,3 & $\mathrm{~S}$ & 30.50 & -77.34 & 589 & -5.3 \\
\hline prn23-11 & 16.52 & 25.8 & 1,2 & $\mathrm{~S}$ & 24.93 & -82.35 & 337 & -45.4 \\
\hline prn03-07 & 16.73 & 30.0 & 1,3 & $\mathrm{~S}$ & 32.59 & -80.65 & 497 & -23.2 \\
\hline prn15-28 & 17.08 & 44.4 & 1 & $R$ & 33.45 & -86.80 & 270 & 84.4 \\
\hline prn13-07 & 17.24 & 27.0 & 1,2 & S & 27.95 & -88.00 & 390 & -28.5 \\
\hline prn04-28 & 17.46 & 29.4 & 1,2 & $\mathrm{R}$ & 27.25 & -88.56 & 562 & -14.4 \\
\hline prn27-28 & 17.76 & 21.6 & 1 & $R$ & 35.66 & -91.42 & 328 & 68.8 \\
\hline prn19-28 & 17.97 & 27.6 & 1,3 & $\mathrm{~S}$ & 37.08 & -89.16 & 441 & -26.4 \\
\hline prn24-28 & 18.10 & 30.0 & 1,3 & $\mathrm{~S}$ & 38.85 & -91.96 & 560 & -2.2 \\
\hline prn09-28 & 18.32 & 21.6 & 1,3 & $\mathrm{R}$ & 37.97 & -95.61 & 260 & 65.9 \\
\hline prn07-28 & 18.96 & 19.8 & 1,2 & $\mathrm{~S}$ & 34.00 & -98.08 & 356 & -50.1 \\
\hline
\end{tabular}




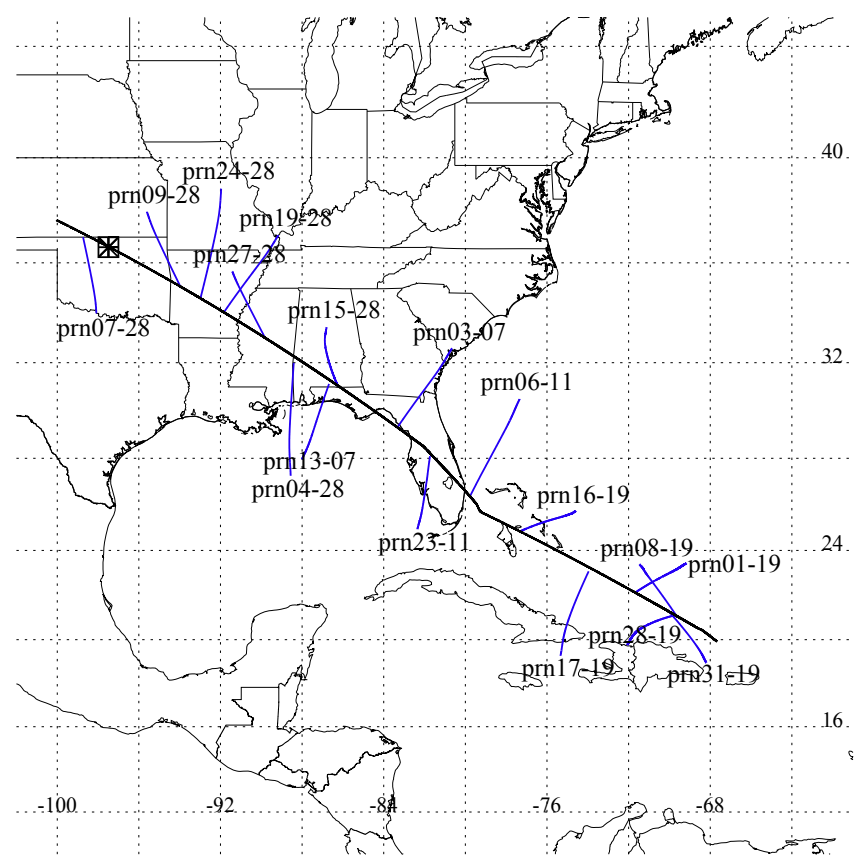

Figure 2. Aircraft flight track (black) from the field station at St. Croix in the US Virgin Islands to the UCAR facility at Broomfield, Colorado, on 2 October 2010. The tangent points (blue) and the PRNs of each ARO occultation are shown. The radiosonde station from Lamont, Oklahoma, is also marked (star).

method (Xie et al., 2008; Haase et al., 2014; Murphy et al., 2015). Two radio-holographic retrieval methods have been implemented for ARO measurements to improve the bending angle retrieval, including the FSI (Adhikari et al., 2016) and the PM method (Wang et al., 2017). A brief description of the three retrieval methods is presented below.

In the GO method, the RO signals are considered to be a series of rays connecting the GPS satellite and the receiver over time. With the assumption of a spherically symmetric atmosphere, each ray has a unique impact parameter, which is the product of the refractive index and the radial distance of the tangent point from the center of local curvature (e.g., Kursinski et al., 1997). The bending angle can be uniquely determined from the precise measurements of ARO receiver and GPS satellite positions and the excess Doppler shift of the GPS signal. After removing the Doppler resulting from the movement of GPS transmitter and receiver, the excess Doppler due to the atmosphere is used for retrieving the bending angle and refractivity profiles (e.g., Lesne et al., 2002; Xie et al., 2008). In regions of highly variable refractivity gradients, which often occur in the moist lower troposphere, multiple rays can arrive at the receiver at the same time and interfere constructively or destructively, which violates the single ray assumption in GO. In that case, the GO method suffers limited vertical resolution and significant refractivity bias. To correctly distinguish these multiple signals, RH retrieval methods are needed.
The FSI method proposed by Jensen et al. (2003) recognizes the RO signal recording as a summation of radio waves of different frequencies and accounts for their interference. Each wave with a unique frequency corresponds to one single ray path in the GO approach. Multiple frequencies present in the signal at a given time can be unambiguously identified by taking the Fourier transform of the RO signal and using the method of stationary phase. This FSI method has been successfully implemented in spaceborne RO retrievals and has significantly improved both the bending and refractivity retrievals as compared to the GO method. The FSI method was adapted for airborne RO simulation and described in Adhikari et al. (2016). FSI requires a perfectly circular trajectory for both transmitter and receiver. Therefore, a geometric correction to the phase is needed to account for the transformation from the real, non-spherical trajectories to circular trajectories referenced to a local center of curvature. The Fourier transform is then applied separately to both the negative and positive elevation angle segments of the ARO measurements to retrieve the ARO bending angle profile for each segment.

The phase-matching (PM) method (Jensen et al., 2004) is another RH method that also utilizes the method of stationary phase (MSP) to calculate the bending angle profile. Instead of frequency, the PM method uses impact parameter to identify individual subsignals. The impact parameter is forwardmodeled during occultation period considering the arbitrary receiver and GPS orbit geometry without the need for the correction required by the FSI method. The PM method was first adapted for ARO by Wang et al. (2017).

Once the ARO bending angle is retrieved from each retrieval method, a modified inverse Abel transformation can then be applied to retrieve the ARO refractivity profile (Xie et al., 2008). There is a singularity in the ARO retrievals nearzero elevation angle (close to aircraft height) where small errors in ray tangent angle can result in large bending angle errors near the receiver altitude (Xie et al., 2008; Adhikari et al., 2016). These errors could propagate downwards and introduce large refractivity errors at the top of the retrieved refractivity profiles. To mitigate this error, the retrieved bending angles in the top $1.5 \mathrm{~km}$ below the receiver altitude are replaced with the simulated bending angle obtained from the collocated ECMWF reanalysis refractivity profile. The dependence on any error in the ERA-I decays exponentially as height decreases. In this paper, the main focus will be on the first results from the analysis of the ARO retrievals using FSI. Comparison among all three retrieval methods will also be presented in Sect. 4.3.

\subsection{ECMWF reanalysis and radiosonde data}

To evaluate the ARO sounding quality, the high-resolution, 6-hourly European Centre for Medium-Range Weather Forecast (ECMWF) Reanalysis - Interim (ERA-I) data were used. The spatial resolution of the reanalysis data is approx- 
imately $80 \mathrm{~km}(\mathrm{~T} 255$ spectral $)$ with uniform grid $\left(0.75^{\circ}\right.$ latitude $\times 0.75^{\circ}$ longitude) on 60 vertical levels from the surface up to $0.1 \mathrm{hPa}$ (Dee et al., 2011). The vertical grid levels are unevenly distributed with more levels at lower altitudes. About half of the model levels (28) are below $10 \mathrm{~km}$, of which 21 levels are below $5 \mathrm{~km}$, and 14 levels are below $2 \mathrm{~km}$. The vertical grid interval increases at higher altitudes, from less than $200 \mathrm{~m}$ below $1 \mathrm{~km}$ to $\sim 500 \mathrm{~m}$ near $5 \mathrm{~km}$.

Given the ERA-I temperature, pressure, and mixing ratio data, the corresponding refractivity $(N)$ can be calculated (Smith and Weintraub, 1953; Healy, 2011). The simulated bending angle profile can be calculated through the Abel integral of the refractivity profile (Xie et al., 2008). Both the ERA-I refractivity and bending angle profiles can then be directly compared with the near-coincident ARO soundings. Due to the long tangent point drift $(\sim 375 \mathrm{~km})$ (Fig. 1), the ARO sounding senses the atmosphere over a large area, which could cover multiple ERA-I grid cells. Therefore, the ERA-I profile within $3 \mathrm{~h}$ of the ARO sounding is first identified, then the refractivity at each ARO TP location is derived through three-dimensional bilinear interpolation of the surrounding eight ERA-I grid values. The comparison is expected to produce an estimate of the combined error of the ARO measurement and the effect of horizontal model variations integrated over the entire ray path.

In addition, the Department of Energy (DOE) Atmospheric Radiation Measurement (ARM) program Central Facility (latitude: $36.62^{\circ} \mathrm{N}$; longitude: $97.48^{\circ} \mathrm{W}$; elevation: $317 \mathrm{~m}$ ), located near Lamont, in north-central Oklahoma, provides data for validation purposes. The core instrumentation at the Southern Great Plains (SGP) site provides radiosonde soundings four times daily, and continuous measurement of surface temperature, pressure, and precipitable water vapor from a microwave radiometer, MWR. For several ARO soundings, two close-by radiosonde soundings were identified, with one at $17: 28 \mathrm{Z}$ and the other at $23: 28 \mathrm{Z}$ on 2 October 2010.

\section{Atmospheric conditions over the study area}

As shown in Table 1, ARO soundings have relatively long duration $(\sim 30 \mathrm{~min})$ and large TP drift $(\sim 375 \mathrm{~km})$. The horizontal variation of the atmosphere needs to be assessed to better understand the ARO measurements. The ARO soundings can be separated into two categories, ones over land (6 soundings) and the others over ocean, including those over coastal regions (11 soundings), based on their tangent point locations. The ARO soundings in the earlier stage of the flight were taken mostly over the ocean/coastal region (14:00-16:40Z), and the soundings at the later stage are mostly over land (17:00-19:00 Z).

Figure 3 shows the ERA-I temperature, moisture, and the refractivity field at two pressure levels $(850$ and $500 \mathrm{hPa})$, at 18:00 Z on 2 October 2010. The synoptic pattern was dom- inated by an upper-level trough stretching from central eastern Canada to the Midwestern United States as seen in the $500 \mathrm{hPa}$ height contours (Fig. 3e). A cold front was located over Oklahoma and orienting northwest across the southeastern US all the way to West Virginia. In contrast, high values of moisture extended from low latitudes up to $\sim 25^{\circ} \mathrm{N}$ over the Caribbean. As a result, very cool and dry conditions were found at the SGP site near the end of the ferry flight, whereas much warmer and more moist conditions were found over the Caribbean (Fig. 3a, b). The slow movement of the cold front into the southern US led to sharp changes in the atmospheric conditions over this region during the $4 \mathrm{~h}$ ferry flight. The large spatial variations in temperature and moisture led to significant inhomogeneity in the refractivity field. Two regions (Fig. 3c, f) were selected to contrast the atmosphere over the warm and moist Caribbean $\left[67-78^{\circ} \mathrm{W}, 18-27^{\circ} \mathrm{N}\right]$ with that of the cool and dry land near the Southern Great Plains of the US [89-99 $\mathrm{W}, 32-40^{\circ} \mathrm{N}$ ]. It is worth noting that the two selected regions do not include the Gulf Coast of Mexico and Florida, which exhibit warm and moist lower troposphere similar to the Caribbean, but rather dry upper troposphere similar to inland region (Fig. 3).

The vertical profiles of the mean moisture and refractivity from ERA-I along with their anomalies and root-meansquare (RMS) difference over the two selected regions are shown in Fig. 4. Over land $\left(89-99^{\circ} \mathrm{W}, 32-40^{\circ} \mathrm{N}\right)$, rather dry atmospheric conditions (mean mixing ratio $<6 \mathrm{~g} \mathrm{~kg}^{-1}$ ) with low near-surface refractivity $(<300 \mathrm{~N}$ units $)$ are observed in the northwestern domain (Fig. 4a, c). The planetary boundary layer (PBL) was moist below $\sim 3 \mathrm{~km}$ with mixing ratios of less than $1.5 \mathrm{~g} \mathrm{~kg}^{-1}$ above this level and a maximum reaching $\sim 6 \mathrm{~g} \mathrm{~kg}^{-1}$ near the surface. Most variation in moisture is seen below $3 \mathrm{~km}$ with a maximum around $2 \mathrm{~km}$, where the RMS difference is close to $2 \mathrm{~g} \mathrm{~kg}^{-1}$ in mixing ratio, resulting in a large variation in refractivity of up to $\sim 10 \%$ (Fig. $4 \mathrm{a}, \mathrm{c}$ ). Above $10 \mathrm{~km}$, water vapor content is low $\left(<0.05 \mathrm{~g} \mathrm{~kg}^{-1}\right)$, and the relatively large variation of refractivity (RMS: $\sim 1 \%$ ) indicates the variability in the upper troposphere over land. It should be noted that the sharp decreases in moisture around 3 and $1 \mathrm{~km}$ leads to large refractivity gradients at both altitudes, which can introduce multipath propagation and result in larger differences between the $\mathrm{GO}$ and $\mathrm{RH}$ refractivity retrievals.

Over the ocean domain $\left(67-78^{\circ} \mathrm{W}, 18-27^{\circ} \mathrm{N}\right)$ extending up to the upper troposphere, the atmosphere is much moister than over land. The moisture exponentially decreases with altitude from a maximum of $\sim 17 \mathrm{~g} \mathrm{~kg}^{-1}$ near the warm ocean surface (with a high surface refractivity of $\sim 380 \mathrm{~N}$ units). The troposphere near $7 \mathrm{~km}$ altitude remains moist with mixing ratio $\sim 1.5 \mathrm{~g} \mathrm{~kg}^{-1}$ (Fig. 4b). The highest moisture variability occurs near $5 \mathrm{~km}$, where the maximum RMS difference reaches $\sim 1.5 \mathrm{~g} \mathrm{~kg}^{-1}$ in mixing ratio, and $\sim 7 \%$ in refractivity. The refractivity above $10 \mathrm{~km}$ shows much less variation over the ocean with a RMS difference $(\sim 0.5 \%)$ only half that found over land $(\sim 1 \%)$. 

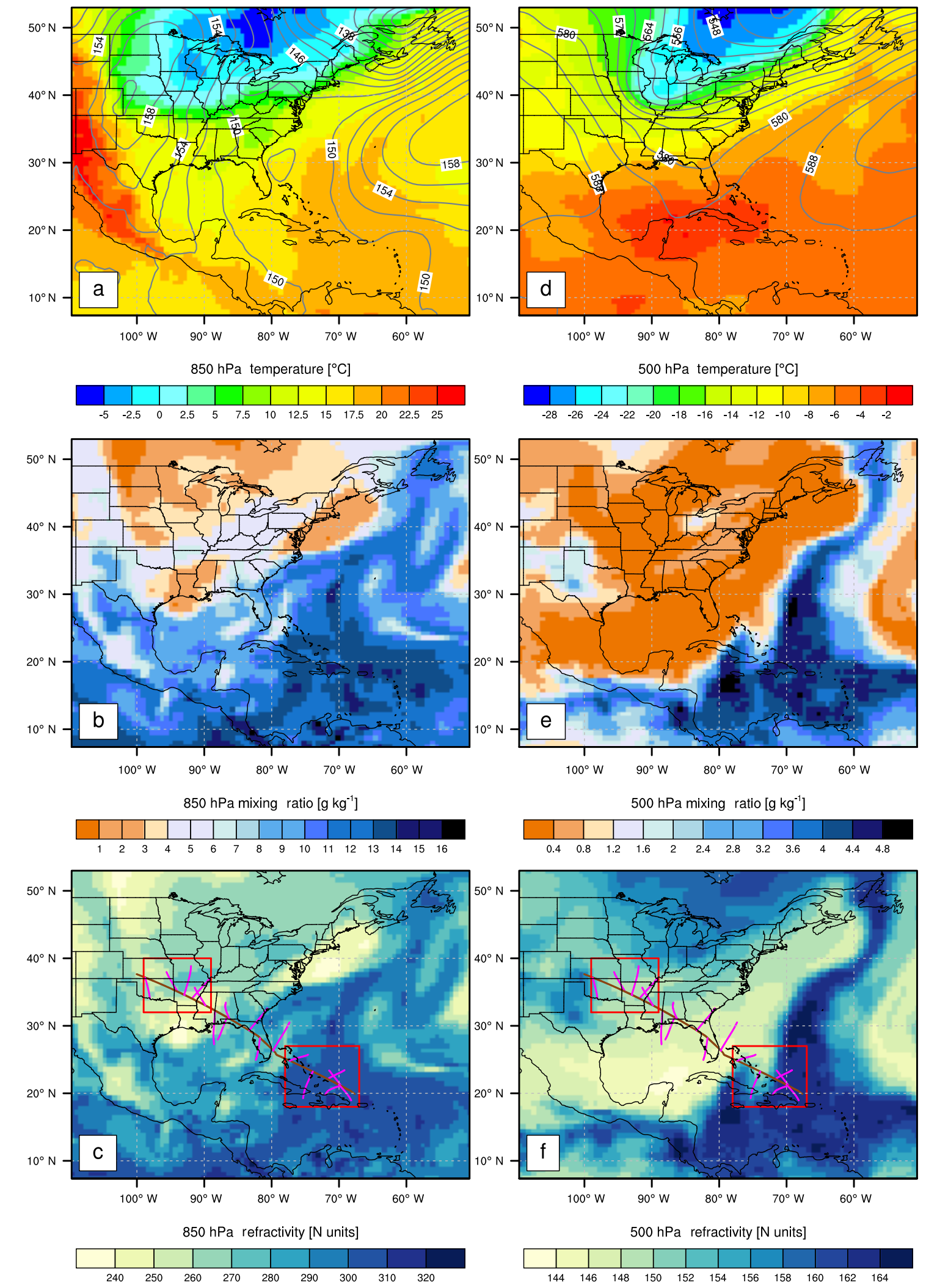

$500 \mathrm{hPa}$ refractivity [N units]

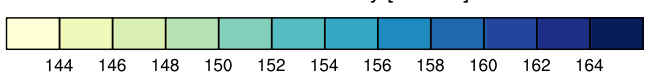

Figure 3. (a, d) ERA-Interim temperature (K) overlaid with the geopotential height contour (dekameters, or tens of meters), (b, e) water vapor mixing ratio $\left(\mathrm{g} \mathrm{kg}^{-1}\right)$, and $(\mathbf{c}, \mathbf{f})$ the derived refractivity $(\mathrm{N}$ units) at $850 \mathrm{hPa}$ and $500 \mathrm{hPa}$, respectively, over the study region at $18: 00 \mathrm{Z}$ on 2 October 2010. Also plotted in (c, f) are the flight track (brown), the ARO tangent points (purple), and the two boxes (red) indicating the selected regions with one over land $\left(89-99^{\circ} \mathrm{W}, 32-40^{\circ} \mathrm{N}\right)$, and the other over the Caribbean sea $\left(67-78^{\circ} \mathrm{W}, 18-27^{\circ} \mathrm{N}\right)$. 

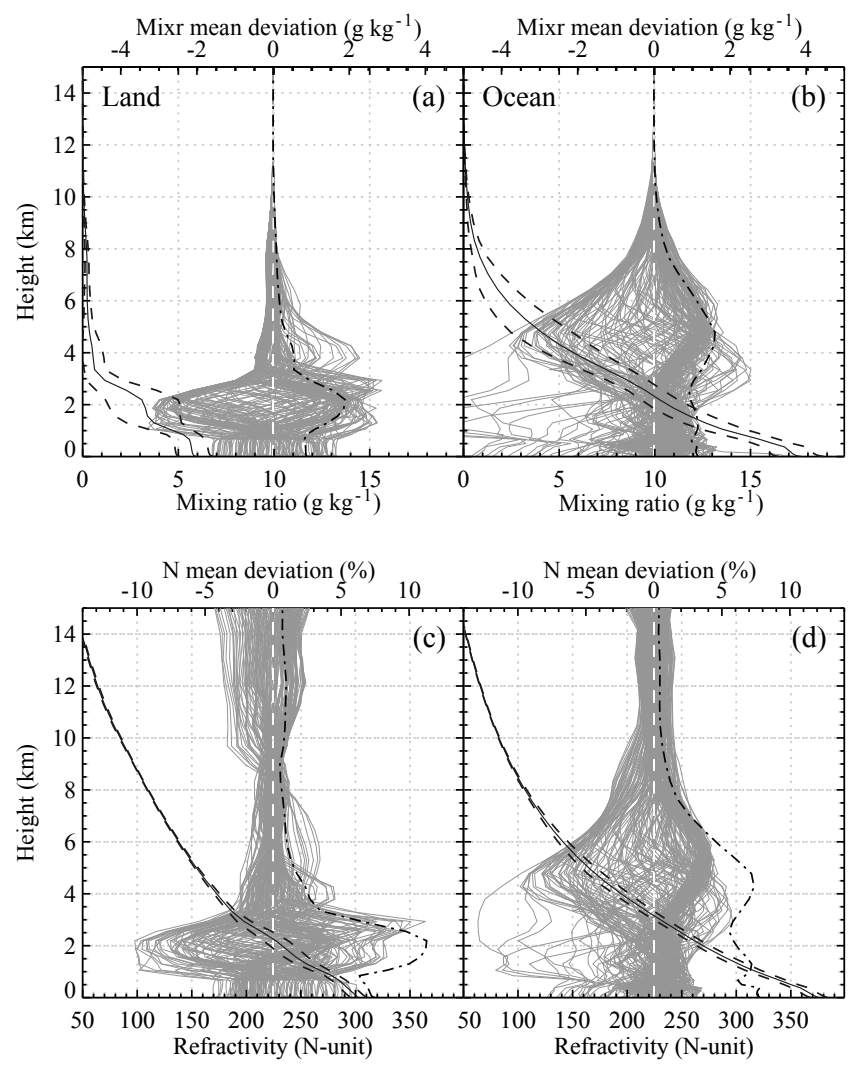

Figure 4. (a) ERA-I mean mixing ratio (Mixr, solid black) and the mean \pm standard deviation (dashed) as well as the anomaly profiles (gray) and their respective RMS profiles (dash-dotted) over land, and (b) over ocean from the two selected regions indicated in Fig. 2c, at 18:00 Z on 2 October 2010. Panels (c) and (d) show the same but for ERA-I refractivity.

\section{Evaluation of the ARO retrievals}

To evaluate the quality of the ARO measurements, the nearcoincident ERA-I reanalysis, and radiosonde soundings were directly compared to the ARO soundings. A quantitative assessment of the ARO retrievals is made through the intercomparison of three different retrieval methods. Moreover, the precision of ARO measurements is evaluated by comparing the same ARO event from the top and side-looking antennas recorded on two independent channels during the ferry flight.

\subsection{Comparison of $\mathrm{ARO}$ retrievals with near-coincident ERA-I profiles}

All 17 ARO measurements recorded from the top antenna (CH1) were processed with the FSI method to retrieve the ARO bending angle profiles, which can be further used for deriving the refractivity profiles. A typical rising ARO event over Alabama, labeled prn15-28 for occulting satellite prn-15 corrected for receiver clock errors by subtracting the residu- als from satellite prn-28, is presented in Fig. 5, along with the near-coincident ERA-I profile. Note the ERA-I bending angle profile is simulated based on the modified forward Abel integration of the refractivity (Xie et al., 2008). For an ARO receiver located inside the atmosphere, the GNSS signals from both the positive and negative elevation angle (typically $\pm 5^{\circ}$ reference to the local horizon) are recorded to retrieve the bending angles from the surface up to the receiver altitude. Assuming a spherically symmetric atmosphere, for every negative elevation ray bending angle, there is a corresponding positive elevation bending angle with the same impact parameter. The partial bending angle, i.e., the difference between the negative and positive elevation bending angle, can then be derived and converted to refractivity through a modified inverse Abel transformation (Healy et al., 2002; Lesne et al., 2002; Xie et al., 2008). For illustration purposes in Fig. 5, the impact height is used, which is simply the difference between the impact parameter and the local curvature radius of the Earth. Because impact height depends on refractivity, it is typically a value of about $2 \mathrm{~km}$ at the surface in the tropics. Note the simulated bending angles from positive elevation angles (e.g., close to $+5^{\circ}$ ) are generally very small, because the GNSS signals go through the relatively dry and low-density atmosphere above the aircraft altitude. The bending angles increase up to $\sim 0.15^{\circ}$ (Fig. $5 \mathrm{~d}$ ) at zero elevation (at the local horizon), when the tangent point of the ray is at the aircraft location at $\sim 13.5 \mathrm{~km}$ altitude (corresponding to the maximum impact height of $\sim 14 \mathrm{~km}$, in Fig. 5d). The bending angles continue to increase at lower negative elevation angle as the GPS signals go through the denser and moister atmosphere.

The ERA-I profile shows a weak temperature inversion with a large moisture gradient near $1 \mathrm{~km}$, which leads to a large refractivity gradient and a sharp increase in bending angle around an impact height of $3 \mathrm{~km}$. Both the ARO bending angle and refractivity profiles are highly consistent with the ERA-I profiles with the mean refractivity difference of about $\sim 0.2 \%$ (RMS $1 \%$ ) overall and less than $0.1 \%$ (RMS $0.5 \%$ ) above $3 \mathrm{~km}$. The ARO sounding retrieved from FSI also captures the PBL height well at about $2.5 \mathrm{~km}$. Larger differences are seen in refractivity below that and in the bending angle below $\sim 4 \mathrm{~km}$ impact height.

The prn15-28 occultation is a rising case, where the ARO receiver tracks the GPS occultation signal from near the surface to the upper atmosphere. For example, the SNR around 17.1 $\mathrm{h} \mathrm{UTC}$ is close to the background noise, when the tangent point is near the surface. Note a sharp drop of ARO SNR at $17.17 \mathrm{~h}$ to the background noise, and the strong signal reemerging at $\sim 17.12 \mathrm{~h}$ in Fig. 5c. The large SNR variation is a strong indication of signal interference due to multipath resulting from the sharp refractivity gradient seen in the ERA-I profiles near $1 \mathrm{~km}$.

After comparing each ARO refractivity profile from the top antenna (CH1) with its near-coincident ERA-I profile, the fractional refractivity differences are shown in Fig. 6. Over- 


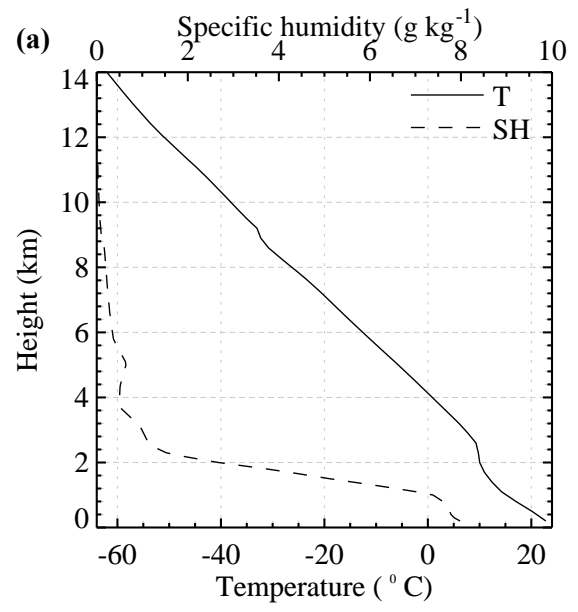

(c)

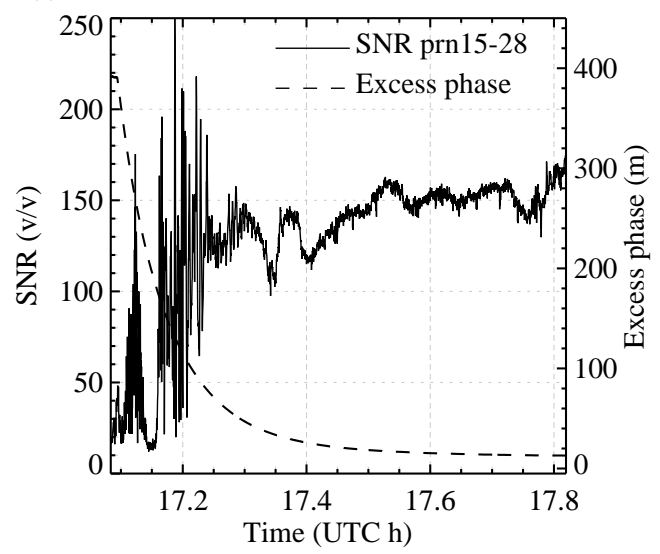

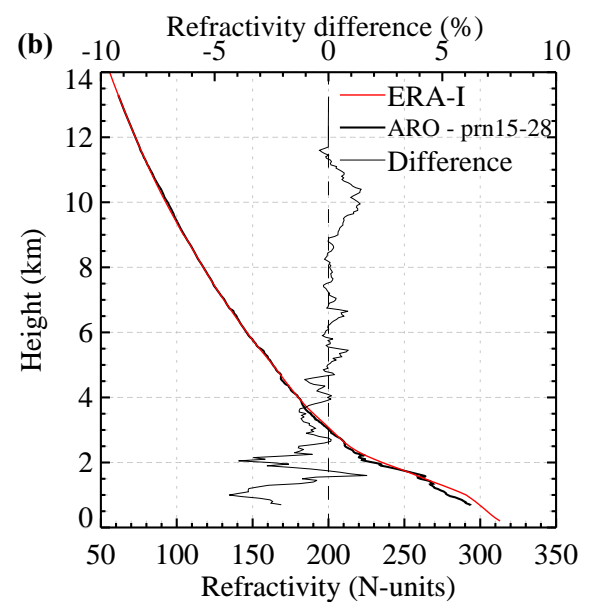
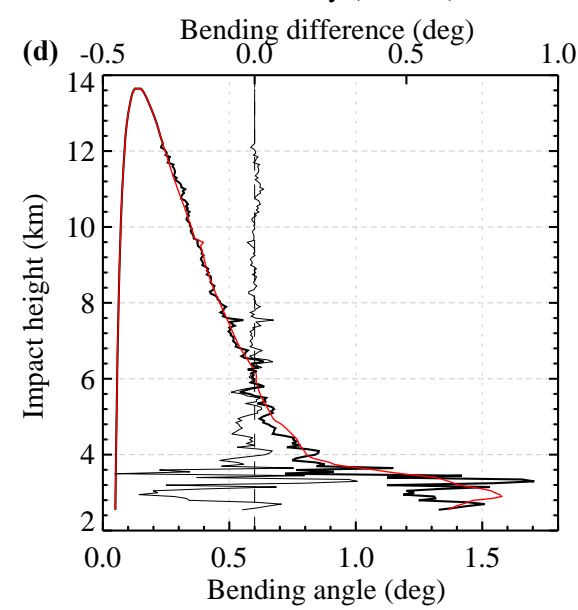

Figure 5. One typical rising ARO sounding (prn15-28) from the top antenna (CH1) with the near-coincident ERA-I profiles, (a) ERA-I temperature and specific humidity profiles; (b) ARO (thick black) and the ERA-I (thick red) refractivity profiles along with their difference (thin black); (c) the SNR and excess phase of the ARO event; and (d) ARO (black) and the simulated ERA-I (red) bending angle profiles and their difference (thin black).

all, the ARO profiles are highly consistent with the ERA-I above $\sim 5 \mathrm{~km}$ with near-zero bias of $-0.15 \%$ (RMS $0.22 \%$ ) in the middle and upper troposphere. In the lower troposphere, however, the ARO refractivity shows a negative bias of about $-1.5 \%$ (RMS $1.7 \%$ ) below $5 \mathrm{~km}$ with a maximum of $-3 \%$ near the surface. As large differences in atmospheric conditions are seen between land and ocean (Fig. 4), we further separate the ARO soundings into two categories with one group of ARO soundings over land (i.e., with all TPs over land) and the others over ocean (i.e., with partial or all TPs over ocean) as shown in Fig. 2. The ARO profiles over ocean show a negative refractivity bias below $5 \mathrm{~km}$ (Fig. 6), where large moisture variations begin in the ERA-I profiles over the ocean (Fig. 4b, d). Similarly, the ARO profiles over land show the negative refractivity bias below $\sim 3.5 \mathrm{~km}$ with a maximum bias near $2 \mathrm{~km}$ (Fig. 6), where the maximum moisture and refractivity variations are observed in ERA-I profiles over land (Fig. 4a, c). Overall, the negative ARO refractivity biases in the lower troposphere seem to be related to the moisture variations. Wang et al. (2016) showed that when refractivity is higher than the climatological value used in the Doppler model for the open-loop tracking, low SNR could potentially lead to an unwrapping error in the carrier phase measurements that would produce a preferentially negatively biased refractivity.

\subsection{ARO retrievals with near-coincident radiosonde measurements}

Near the end of the ferry flight, there are two ARO profiles (prn09-28 and prn07-28) near the SGP site at Lamont, Oklahoma (Fig. 2), where radiosonde profiles were launched at 17:28 and 23:28Z on 2 October 2010 (Fig. 7). The vertical profiles of temperature, relative humidity and the derived refractivity for the two soundings are shown in Fig. 7a, b. The radiosonde around at 17:28 Z, or 23:28 local time (LT), shows a complicated multiple layer structure. Three distinct 


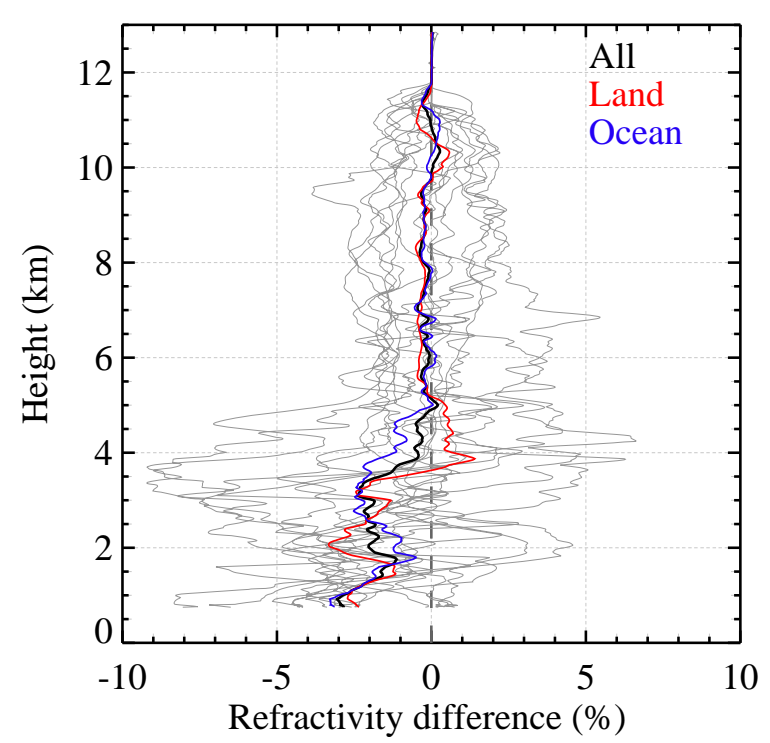

Figure 6. Fractional refractivity difference between the ARO (CH1) FSI retrievals and the near-coincident ERA-I profiles. Each thin gray line represents an individual occultation, and the three thick lines represent the mean difference for all profiles (black) and the profiles over land (red) and over ocean (blue), respectively.

layers marked by high relative humidity gradients and weak inversions are seen at around $1.3,1.7$, and $2.7 \mathrm{~km}$, where large negative refractivity gradients are also present. On the other hand, the radiosonde in the late afternoon (at 23:28 Z, or 17:28 LT) shows a well-defined single layer PBL with a sharp inversion and large relative humidity and refractivity gradient at $\sim 1.9 \mathrm{~km}$. Note that the sharp refractivity gradient exceeds the critical refraction of $-157 \mathrm{~N}$ units $\mathrm{km}^{-1}$ and leads to a ducting layer across the PBL inversion layer.

The time series of the surface temperature and relative humidity as well as the precipitable water vapor (PWV) from the microwave radiometer shows the high-pressure system was moving into the area. The cold front caused significant change around 18:00 Z and strong subsidence and drying afterward, which creating a stronger boundary layer inversion at the radiosonde station in late afternoon (Fig. 7c, d). Near local noon (18:00 Z), relatively stable surface temperature but a rapid decrease in PWV are observed. During the one hour time span from 17:30 to $18: 30 \mathrm{Z}$, the PWV decreased by $38 \%$ from 1.6 to $1.0 \mathrm{~cm}$ (a decrease of $0.6 \mathrm{~cm}$, or $\sim 6 \mathrm{~kg} \mathrm{~m}^{-2}$ ). The PWV further decreased to $\sim 0.7 \mathrm{~cm}$ at 19:00 Z and remained rather constant into the late afternoon (23:00 Z, or 17:00 LT). Most of the water vapor is found in the boundary layer as seen in Fig. 7a, b. The significant change in the PWV near the radiosonde launch time at 17:28 Z but rather small variation at 23:28 Z implies larger temporal variation of the lower tropospheric (or PBL) structure near local noon time (17:28 Z) as compared to the late afternoon (23:28Z).
The bending angle profiles of the two ARO measurements from prn07-28 (at 18:57 Z, Fig. 8a) and prn09-28 (at 18:19 Z, Fig. 8 b) are presented along with the simulated bending angle profiles from the collocated radiosonde and ERA-I profiles at 17:28 and 23:28 Z, respectively. The refractivity profiles and the difference between the ARO and the radiosonde/ERAI profiles are also shown in Fig. 8c, d, respectively. The two radiosonde soundings are almost identical in refractivity above $\sim 4 \mathrm{~km}(0.7 \%$ RMS ) but show large differences (up to $\sim 15 \%$ near $2.5 \mathrm{~km}$ ) inside the boundary layer (Fig. 8d) due to the strong temporal variation of atmospheric conditions resulting from the synoptic forcing and the local diurnal surface heating changes (Figs. 3 and 7).

The radiosonde at noon (17:28Z) shows three jumps in bending angle at $\sim 3,4$, and $4.5 \mathrm{~km}$ impact height and a small increase in bending at $\sim 6 \mathrm{~km}$. On the other hand, the late afternoon sounding (at 23:28 Z, or 18:28 LT) shows only one large jump in bending angle at $\sim 3.5 \mathrm{~km}$ impact height (Fig. 8b). It is important to note that even though the two ARO soundings are collected around the same time, the ARO prn09-28 sampled the PBL in northern Oklahoma, where the cold air mass associated with the high-pressure system was already dominant, whereas the ARO prn07-28 sampled the PBL in southern Oklahoma, when the cold front had just moved in and caused dramatic changes as seen in the in situ measurements at Lamont, Oklahoma (Fig. 7).

The ARO profile (prn07-28) is about $1.5 \mathrm{~h}$ later and $290 \mathrm{~km}$ south of the radiosonde (RDS1728Z). It also detects distinctly sharp bending angle near $3,4,4.5$, and $6 \mathrm{~km}$ impact height (Fig. 8a). These correspond to the bending angles jumps seen in the radiosonde (RDS1728Z) but with slightly underestimated bending beneath each layer. Despite capturing the height of the individual layers, and showing agreement above $8 \mathrm{~km}(\sim 0.9 \%$ RMS in refractivity), the ARO and the radiosonde refractivity differences are significant at lower levels, showing RMS difference $\sim 2 \%$ in the height range 4 $8 \mathrm{~km}$, and a maximum difference up to $-9 \%$ at $\sim 2.5 \mathrm{~km}$. In addition, a slightly better agreement between the ARO and the ERA-I profiles is seen.

The ARO profile (prn09-28) is a similar distance, about $250 \mathrm{~km}$ north of the radiosonde site, but is about $5 \mathrm{~h}$ earlier than the radiosonde (RDS2328Z) observation. However, remarkable consistency between the two in both bending angle and refractivity is shown above $2 \mathrm{~km}$ (less than $0.5 \%$ RMS in refractivity), with a large negative bias (up to $-10 \%$ ) in refractivity below $\sim 2 \mathrm{~km}$. This signature in the bending angle profile is typical in the presence of a ducting layer across a sharp inversion layer (Fig. 7b), which could introduce large negative refractivity biases in standard Abel retrieval due to the non-unique inversion problem (Sokolovskiy, 2003; Xie et al., 2006). The ARO sounding shows one large bending angle jump near $3.5 \mathrm{~km}$ impact height, corresponding to the sharp refractivity gradient near $2 \mathrm{~km}$ that is also observed by the radiosonde. Beneath this height, the ARO bending angle is smaller than the radiosonde bending, which results in a neg- 

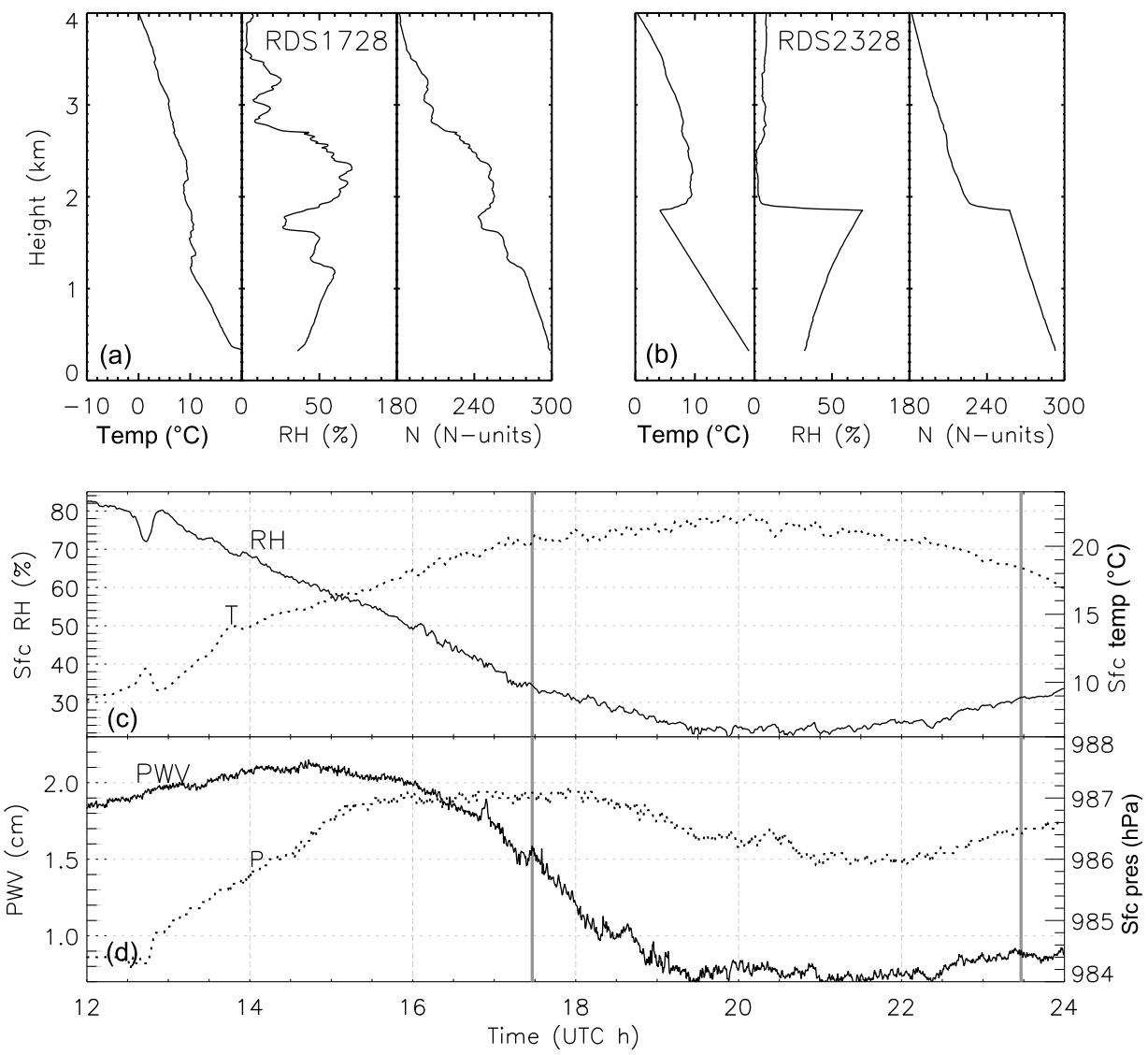

Figure 7. (a, b) Vertical profiles of temperature (Celsius), relative humidity (\%), and refractivity ( $\mathrm{N}$ units) for radiosonde profiles at 17:28 and 23:28 Z, respectively; (c) time series of the surface relative humidity and temperature; and (d) surface pressure and precipitable water vapor (PWV) from the microwave radiometer, from the radiosonde station at Lamont, Oklahoma, on 2 October 2010. The two vertical gray lines mark the time at 17:28 and 23:28 Z.

ative refractivity bias below $2 \mathrm{~km}$. Moreover, the ARO profile agrees extremely well with the collocated ERA-I profile, including a much smaller difference inside PBL below $2 \mathrm{~km}$ (Fig. 8d). Both the ARO and the collocated ERA-I profile show a smaller refractivity gradient without a ducting layer as observed in the radiosonde profile (RDS2328Z) near $2 \mathrm{~km}$. The better agreement between ERA-I and the ARO measurement implies the likely presence of the horizontal inhomogeneity inside the PBL over the region, where the fine vertical structure observed from the in situ radiosonde might not be representative of a large domain (e.g., 100-200 km horizontally), and could be smoothed out in the ARO observation.

\subsection{Comparison of ARO profiles derived from different retrieval methods}

As described in Sect. 2.1.2, there are three major ARO retrieval methods, including the GO and two radio-holographic methods that were used to retrieve the bending angle profiles. The ARO measurements recorded from the top antenna (CH1) are separated once again into land and ocean cate- gories, based on the tangent point locations. Figure 9 shows the mean difference between the ARO profiles from the three methods and the near-coincident ERA-I profiles using ERAI as the reference. The differences for both the ARO bending angle (Fig. 9a, b) and refractivity (Fig. 9c, d) retrievals over land and ocean are shown separately. Furthermore, the fractional refractivity differences between the GO/PM retrievals and FSI are shown in Fig. 9e, f.

The ARO bending angle profiles from all three retrieval methods display small difference from the near-coincident ERA-I profiles above $\sim 6.5 \mathrm{~km}$ over land (Fig. 9a) and above $\sim 8 \mathrm{~km}$ over ocean (Fig. 9b) in impact height. Correspondingly, the small RMS fractional refractivity difference is about $0.3 \%$ above $\sim 5 \mathrm{~km}$ over both land and ocean (Fig. $9 \mathrm{c}$, d). Below these levels, all three retrieval methods show negative biases increasing at lower altitude. The GO retrieval deviates significantly from the FSI and PM retrievals and shows larger negative biases in bending and refractivity due to the apparent multipath problem resulting from the increasing moisture in the lower troposphere (e.g., Murphy et al., 2015). The higher transition altitude for large GO retrieval 

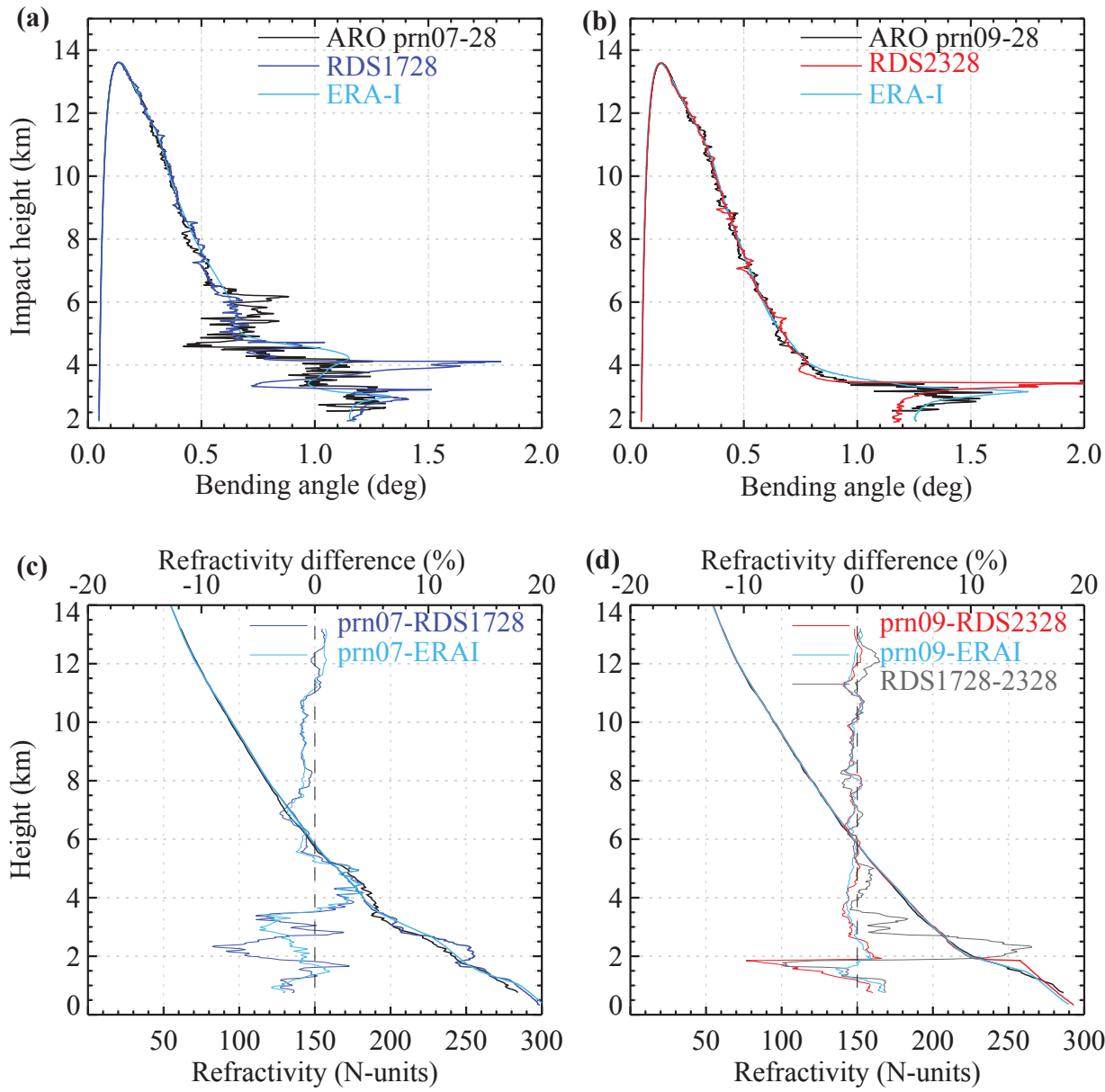

Figure 8. ARO (CH1) bending angle profiles for (a) prn07-28 and (b) prn09-28 along with the simulated bending angle of the near-coincident ERA-I and radiosonde profiles at 17:28 and 23:28 Z on 2 October 2010, respectively. (c, d) The refractivity profiles of ARO, radiosonde, and ERA-I and their difference including the fractional refractivity difference between the two radiosonde in (d).

bias indicates the multipath problem is worse for $\mathrm{GO}$ over ocean $(\sim 7 \mathrm{~km})$ than land $(\sim 5.5 \mathrm{~km})$ as may be expected from the height dependence of the moisture variability in Fig. 4. All three ARO refractivity (and bending) retrievals reach the maximum biases at around $2.5 \mathrm{~km}$ over land and at $4 \mathrm{~km}$ over ocean, where the maximum moisture variations are observed in the lower troposphere, respectively (Fig. 4). The RMS refractivity difference between PM and FSI is less than $0.1 \%$ above $5 \mathrm{~km}$ and increases slightly at lower levels over land (Fig. 9e). The negative refractivity bias below $5 \mathrm{~km}$ is slightly greater for PM retrievals over ocean compared to FSI. However, given the variability and the small number of profiles over ocean analyzed in Fig. 9f, this may not be significant.

The remaining negative bending angle and refractivity biases in the moist lower troposphere in FSI and PM retrieval (Fig. 9c, d) may be due to low SNR in the lowest levels of the atmosphere. The effects of SNR can be examined by investigating the differences among antennas that are described in the next section.

\subsection{ARO antenna evaluation and measurement precision}

Out of the 17 ARO events recorded from the top antenna (Table 1), there are 12 ARO events that are simultaneously recorded from one of the two side-looking antennas. The others occurred with a viewing azimuth directly fore or aft of the aircraft. Four were recorded from the port $(\mathrm{CH} 2)$ and eight from starboard (CH3) antenna (Table 1). The redundant measurements provide a unique opportunity to estimate the precision of the ARO measurements and evaluate the key factors affecting the GPS occultation signal tracking. Note the isotropic top antenna had much better recordings of the high-elevation GPS satellites than the side-looking antenna. For each ARO event, the same high-elevation GPS satellite tracked by the top antenna was used for clock calibration of the occultation measurements from both the top and sidelooking antennas. In addition, same processing procedure were applied to the individual channels from side and top antennas for the open-loop tracking, filtering, FSI retrieval, and 

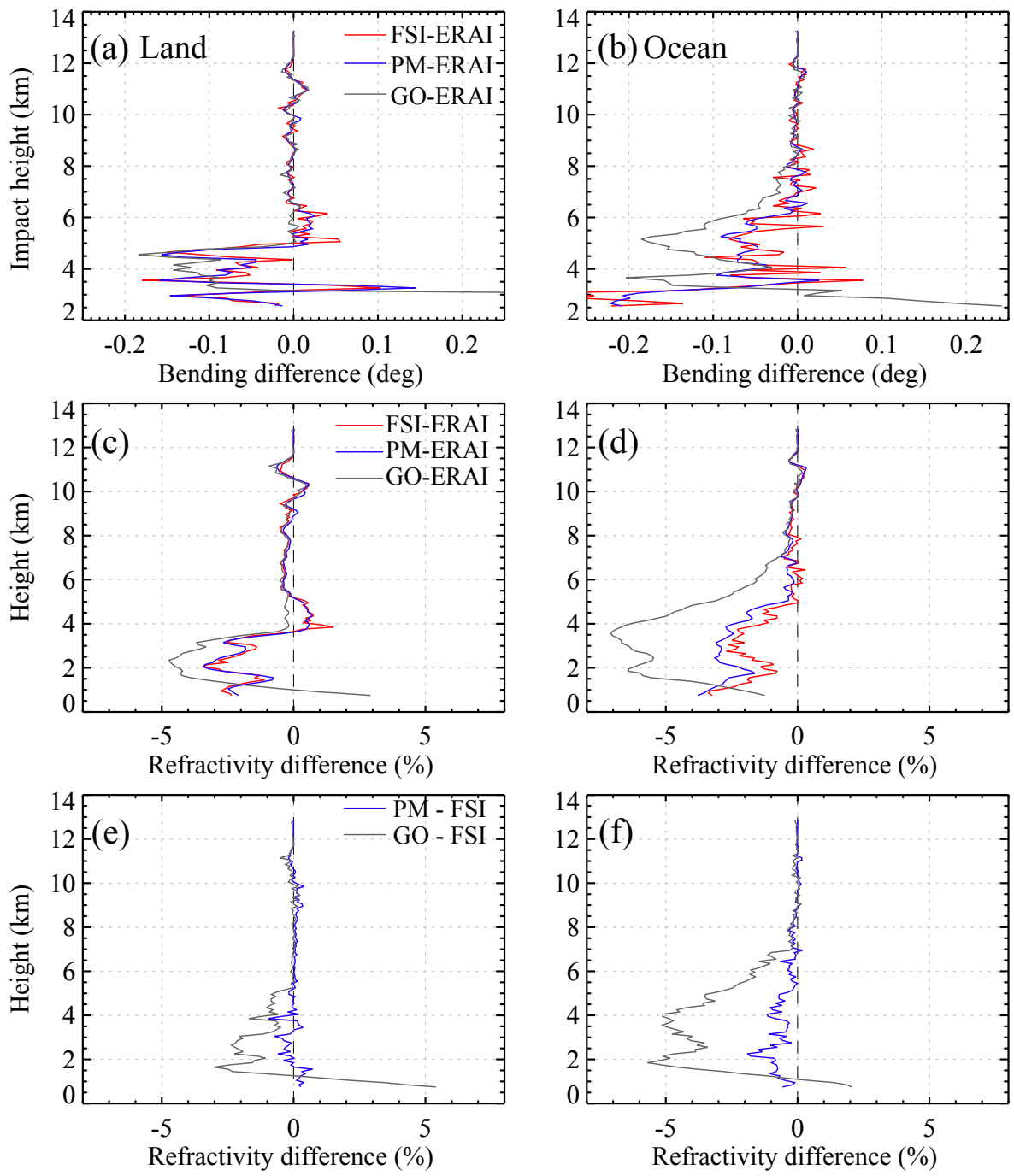

Figure 9. (a, b) The difference between ARO (CH1) bending angle from three retrieval methods (FSI, PM, and GO) and the simulated bending angle of near-coincident ERA-I profiles; (c, d) fractional refractivity difference between ARO retrievals and ERA-I profiles; (e, f) fractional refractivity difference of GO and PM retrievals from the FSI retrieval, over land and ocean, respectively.

Abel inversion, to derive the bending angle and refractivity profiles.

Figure 10 shows the difference between the ARO refractivity retrievals from the side and the top antennas. The individual refractivity difference profiles for each ARO event and the mean difference are shown. Note there is one obvious outlier (prn16-19), which shows a large negative refractivity difference below $3 \mathrm{~km}$ reaching $-10 \%$ near the surface. Without considering the outlier case, the RMS refractivity difference is less than $\sim 0.1 \%$ above $3 \mathrm{~km}$ and $0.2 \%$ overall from the surface up to $1.5 \mathrm{~km}$ below the flight level. There is a small positive bias from 0 to $4 \mathrm{~km}$, with a maximum of $\sim 0.5 \%$ near $3 \mathrm{~km}$. The small retrieval difference between the ARO measurements from the top and the side-looking antennas indicates high precision in the raw ARO measure- ments can be achieved, corresponding to an RMS better than $0.2 \%$ in refractivity (or $\sim 0.4 \mathrm{~K}$ ).

The refractivity retrieval differences between the top and side antennas for each ARO event (Fig. 10), are likely caused by differences in the SNR of the two ARO signals, which results in noise variations in the phase extracted in the openloop tracking procedure (Wang et al., 2016). Although the side-looking antennas had higher gain in the view direction perpendicular to the aircraft, the line of sight to the GPS satellite was rarely in that direction and often appeared in part of the antenna pattern with lower gain. The antenna directivity limits has lower gain in the fore and aft directions (Fig. 1). However, the wide-view top antenna generally maintains high SNR until the lowest elevation angle measurements when the tangent point descends into the lower 


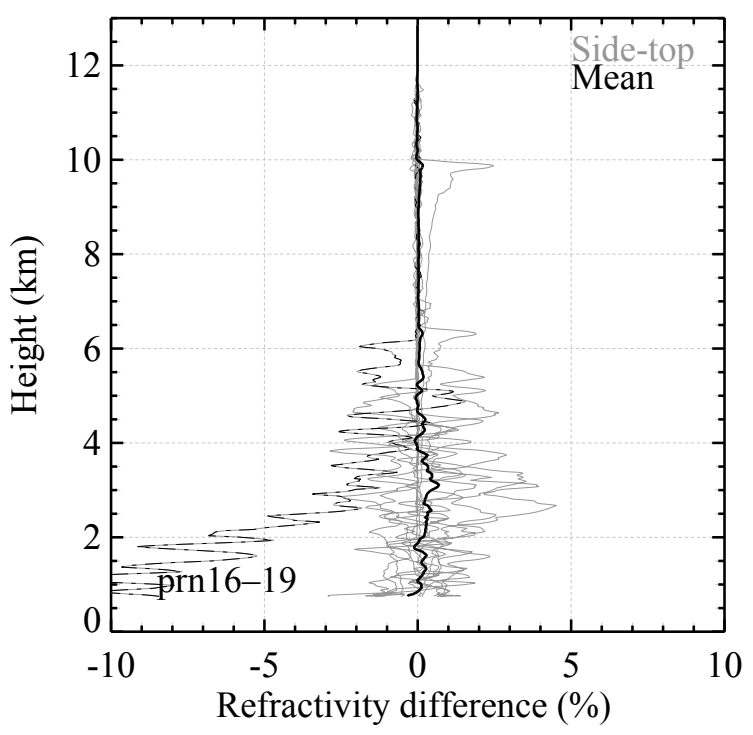

Figure 10. The individual refractivity difference profiles (thin gray) between the ARO retrieval from side-looking antenna $(\mathrm{CH} 2$ or $\mathrm{CH} 3)$ and the top antenna $(\mathrm{CH} 1)$, which both track the same occulting GPS satellite. Also shown is the mean refractivity difference (thick black) that ignores the outlier case, prn16-19 (dashed), with large negative difference.

troposphere. It permits observations of GPS satellites at the full $360^{\circ}$ range of azimuth angles.

Figure 11a and c show the outlier case (prn16-19) from Fig. 10 that displays large negative refractivity difference between the side (starboard) antenna (CH3) and the top antenna (CH1). The SNR measured from both antennas are shown in Fig. 11a. In comparison to the top antenna, the side-looking antenna shows generally lower SNR with large variation during the setting occultation. It started tracking prn16 at about $-50^{\circ}$ azimuth angle relative to the antenna boresight direction (negative sign indicating toward the rear of the aircraft) at $15.75 \mathrm{~h}$ (UTC), i.e., about $40^{\circ}$ from the back of the aircraft. The azimuth angle further increases to over $-55^{\circ}$ near $15.9 \mathrm{~h}$, which led to a significant drop of the SNR close to the noise floor. The SNR thereafter recovered slightly but dropped again to near the noise floor $(\sim 20 v / v)$ at around $16.16 \mathrm{~h}$ (UTC) with azimuth angle over $-60^{\circ}$, whereas the top antenna maintained relative high SNR above $\sim 80(v / v)$. Such low SNR (CH3) can result in incorrectly resolved phase unwrapping and introduce a usually negative bias, in the reconstructed signal phase (Fig. 11c), which further leads to a negative bias in the ARO bending and refractivity retrievals (Wang et al., 2016).

On the other hand, a typical normal case (prn01-19) is also shown (Fig. 11b, d). With the occulting GPS satellite near the boresight of the side-looking antenna (e.g., azimuth angle of -48 to $-56^{\circ}$ ), the SNR from the side-looking antenna shows higher SNR than the top antenna. The excess phase difference between the two antennas remains very small dur- ing the ARO event and only has some small differences in the lowest troposphere (Fig. 11d), which does not introduce significant differences in the bending angle and refractivity retrievals.

\section{Summary and conclusions}

The airborne radio occultation technique can offer dense RO soundings over targeted regions during mesoscale and transient weather events, with comparable data quality to the spaceborne RO soundings in the mid- to upper troposphere. In this study, the airborne radio occultation measurements from the $4 \mathrm{~h}$ long $(\sim 3600 \mathrm{~km})$ ferry flight from the Virgin Islands to Colorado at the end of the PREDICT field campaign were analyzed, and the quality of the ARO retrievals was evaluated. During the ferry flight, the aircraft was cruising at a steady altitude of approximately $13 \mathrm{~km}$ along a nearly straight flight path, which provided the ideal recording geometry for ARO measurements from side-looking antennas. The ARO sampled the warm and moist Caribbean environment to the cool and dry continental environment near the Southern Great Plains of the US. A total of 17 ARO soundings were recorded by the top antenna, among which 12 ARO soundings were simultaneously recorded by the side-looking antennas. The ARO soundings take an average of $29 \mathrm{~min}$ to sense from $5^{\circ}$ above the aircraft local horizon down to the surface with an average TP drifting distance of $375 \mathrm{~km}$. The GO, the FSI, and the PM methods are used to retrieve the ARO bending angle profiles, which are then used to derive the refractivity though the modified Abel inversion (Xie et al., 2008). The quality of ARO sounding profiles is assessed in detail by comparison with the near-coincident independent datasets, including the ERA-I reanalysis, and radiosonde soundings.

Comparison of ARO FSI refractivity retrievals with the collocated ERA-I profiles shows near-zero refractivity bias of $-0.15 \%$ (RMS $<0.22 \%$ ) in the middle and upper troposphere from $5 \mathrm{~km}$ up to about $11.5 \mathrm{~km}(\sim 1.5 \mathrm{~km}$ below the aircraft altitude). In the lower troposphere, however, the ARO refractivity shows a negative bias of about $-1.5 \%$ (RMS $1.7 \%$ ) below $5 \mathrm{~km}$ with a maximum bias near $4 \mathrm{~km}$ over ocean and near $2 \mathrm{~km}$ over land (Fig. 6), corresponding to the altitude of maximum moisture gradients for ocean and land (Fig. 4), respectively.

The ARO soundings also agree well with the nearcoincident radiosonde above $4 \mathrm{~km}$ and capture the heights of sharp layers in the PBL and the variations observed by the radiosondes during the cold frontal passage (Fig. 8). The underestimation of the ARO bending angle in the PBL leads to a negative bias in refractivity compared to the radiosonde. However, the smaller difference between ARO and ERA-I profiles indicates that ARO succeeds in representing the refractivity at this larger scale domain. 

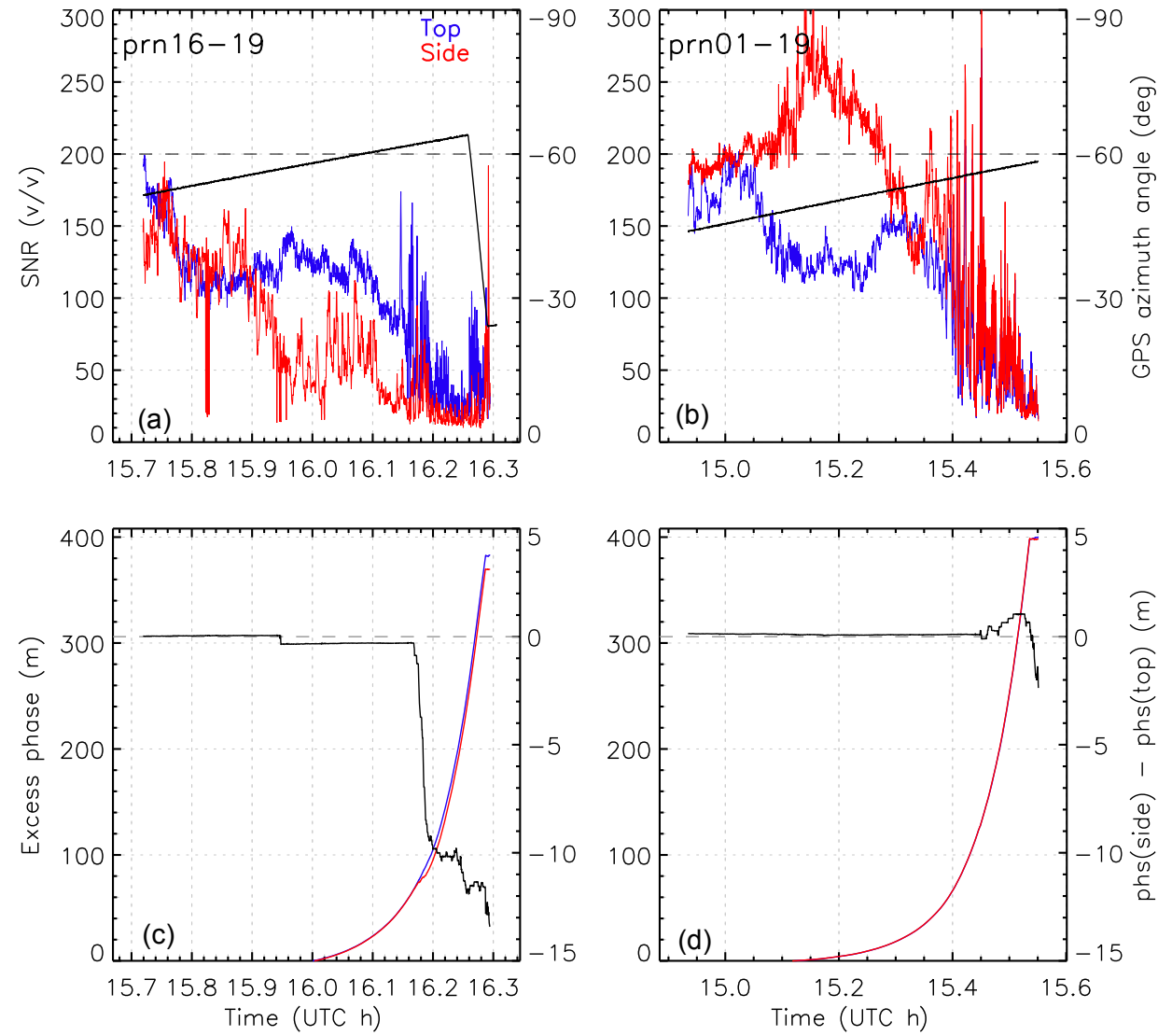

Figure 11. The SNR and the azimuth angle relative to the antenna boresight direction for the occulting satellite (a) prn16 and (b) prn01, recorded from the top $(\mathrm{CH} 1$, blue $)$ and the side-looking $(\mathrm{CH} 3$, starboard, red) antennas; the two horizontal dashed lines indicate the azimuth angle of $-60^{\circ}$; (c, d) the excess phase for both antennas and their difference (black), and the two dashed lines indicate the zero phase difference.

The ARO retrieval uncertainty due to the bending angle retrieval methods is also evaluated. The ARO profiles from all three retrieval methods display small RMS refractivity difference with less than $0.3 \%$ above $\sim 5 \mathrm{~km}$ over both land and ocean, compared with the near-coincident ERA-I profiles (Fig. 9c, d). Below these levels, all three retrievals show negative biases which increase at lower altitude. The FSI and PM retrieval methods significantly reduce the negative refractivity bias seen in the GO retrieval by addressing the multipath problem. The remaining biases below $\sim 4 \mathrm{~km}$ warrant further investigation.

Analysis of the 12 ARO events that were simultaneously recorded from the top and side-looking antennas shows that highly consistent ARO measurements are achieved. The overall RMS refractivity difference is less than $\sim 0.1 \%$ above $3 \mathrm{~km}$ and $\sim 0.2 \%$ overall. There is a small positive bias below $4 \mathrm{~km}$ with a maximum up to $\sim 0.5 \%$ near $3 \mathrm{~km}$. The small retrieval difference in ARO measurements from multiple independent antennas indicates high precision in the raw ARO measurements can be achieved, corresponding to an RMS difference better than $0.2 \%$ in refractivity (or $\sim 0.4 \mathrm{~K}$ ). One outlier case shows the limited occultation satellite visibility of the side-looking antenna at large azimuth angle. The low SNR results in unwrapping errors in the carrier phase measurements that produce a negative bias in the ARO bending and refractivity retrievals.

In summary, the ARO measurements by GISMOS from this ferry flight demonstrate its capability of providing relatively dense soundings for targeting synoptic to mesoscale weather systems. The radio-holographic retrieval methods significantly improve the ARO retrieval in the moist lower troposphere where frequent multipath occurs and otherwise causes large negative biases in the GO retrieval. The ARO soundings capture well the height of sharp refractivity gradients in the moist lower troposphere, especially inside the PBL. The remaining negative bias in ARO bending angle and refractivity in the moist lower troposphere is most likely a result of low SNR, which may be best addressed with improved antenna design. The data reveal the presence of sharp moisture gradients and boundary layer ducting phenomena that warrant further attention. The surprisingly good quality of ARO measurements from a simple omnidirectional zenith 
antenna greatly simplifies the implementation of the ARO system and increases the feasibility of developing an operational tropospheric sounding system onboard commercial aircraft in the future, which could provide a large number of data for direct assimilation in numerical weather prediction models.

Data availability. The data generated in this study are available from the corresponding author upon request.

Competing interests. The authors declare that they have no conflict of interest.

Special issue statement. This article is part of the special issue "Observing Atmosphere and Climate with Occultation Techniques - Results from the OPAC-IROWG 2016 Workshop". It is a result of the International Workshop on Occultations for Probing Atmosphere and Climate, Leibnitz, Austria, 8-14 September 2016.

Acknowledgements. Funding for this research was provided by NSF grant AGS-1262041 and NASA grant NNX15AQ17G. Jennifer S. Haase was supported by NSF grant AGS-1015904 and NASA grants NNZ12AQ86G/NNX12AK30G. We also thank Michael Murphy from the University of California, San Diego, and the anonymous reviewers for their valuable comments and suggestions to improve the quality of the manuscript. The in situ surface measurement and radiosonde data were provided by the Department of Energy (DOE) Atmospheric Radiation Measurement (ARM) program. ERA-Interim reanalysis profiles were provided by the European Centre for Medium Range Forecasts (ECMWF).

Edited by: Sean Healy

Reviewed by: two anonymous referees

\section{References}

Adhikari, L., Xie, F., and Haase, J. S.: Application of the full spectrum inversion algorithm to simulated airborne GPS radio occultation signals, Atmos. Meas. Tech., 9, 5077-5087, https://doi.org/10.5194/amt-9-5077-2016, 2016.

Anthes, R. A.: Exploring Earth's atmosphere with radio occultation: contributions to weather, climate and space weather, Atmos. Meas. Tech., 4, 1077-1103, https://doi.org/10.5194/amt-4-10772011, 2011.

Anthes, R. A., Bernhardt, P. A., Chen, Y., Cucurull, L., Dymond, K. F., Ector, D., Healy, S. B., Ho, S. P., Hunt, D. C., Kuo, Y.-H., Liu, H., Manning, K., McCormick, C., Meehan, T. K., Randel, W. J., Rocken, C., Schreiner,W. S., Sokolovskiy, S. V., Syndergaard, S., Thompson, D. C., Trenberth, K. E., Wee, T. K., Yen, N. L., and Zeng, Z.: The COSMIC/FORMOSAT3 Mission-Early results, B. Am. Meteorol. Soc., 89, 313-333, https://doi.org/10.1175/BAMS-89-3-313, 2008.
Ao, C. O.: Effect of ducting on radio occultation measurements: An assessment based on high-resolution radiosonde soundings, Radio Sci., 42, RS2008, https://doi.org/10.1029/2006RS003485, 2007.

Ao, C. O., Meehan, T. K., Hajj, G. A., Mannucci, A. J., and Beyerle, G.: Lower troposphere refractivity bias in GPS occultation retrievals, J. Geophys. Res., 108, 4577, https://doi.org/10.1029/2002JD003216, 2003.

Ao, C. O., Hajj, G. A., Meehan, T. K., Dong, D., Iijima, B. A., Mannucci, A. J., and Kursinski, E. R.: Rising and setting GPS occultations by use of open-loop tracking, J. Geophys. Res., 114, D04101, https://doi.org/10.1029/2008JD010483, 2009.

Beyerle, G., Schmidt, T., Wickert, J., Heise, S., Rotacher, M., König-Langlo, G., and Lauritsen, K. B.: Observations and simulations of receiver-induced refractivity biases in GPS radio occultation, J. Geophys. Res., 111, D12101, https://doi.org/10.1029/2005JD006673, 2006.

Cucurull, L. and Derber, J. C.: Operational implementation of COSMIC observations into NCEP's Global Data Assimilation System, Weather Forecast., 23, 702-711, https://doi.org/10.1175/2008WAF2007070.1, 2008.

Dee, D. P., Uppala, S. M., Simmons, A. J., Berrisford, P., Poli, P., Kobayashi, S., Andrae, U., Balmaseda, M. A., Balsamo, G., Bauer, P., Bechtold, P., Beljaars, A. C. M., van de Berg, L., Bidlot, J., Bormann, N., Delsol, C., Dragani, R., Fuentes, M., Geer, A. J., Haimberger, L., Healy, S. B., Hersbach, H., Hólm, E. V., Isaksen, L., Kållberg, P., Köhler, M., Matricardi, M., McNally, A. P., Monge-Sanz, B. M., Morcrette, J.-J., Park, B.-K., Peubey, C., de Rosnay, P., Tavolato, C., Thépaut, J.-N., and Vitart, F.: The ERA-Interim reanalysis: Configuration and performance of the data assimilation system, Q. J. Roy. Meteor. Soc., 137, 553-597, https://doi.org/10.1002/qj.828, 2011.

Garrison, J. L., Walker, M., Haase, J., Lulich, T., Xie, F., Ventre, B. D., Boehme, M. H., Wilmhoff, B., and Katzberg S. J.: Development and testing of the GISMOS instrument, Geoscience and Remote Sensing Symposium, IGARSS 2007, IEEE International, 5105-5108, 23-28 July 2007, https://doi.org/10.1109/IGARSS.2007.4424010, 2007.

Haase, J. S., Murphy, B. J., Muradyan, P., Nievinski, F. G., Larson, K. M., Garrison, J. L., and Wang, K.-N.: First results from an airborne GPS radio occultation system for atmospheric profiling, Geophys. Res. Lett., 40, 1759-1765, https://doi.org/10.1002/2013GL058681, 2014.

Healy, S. B., Haase, J., and Lesne, O.: Letter to the Editor Abel transform inversion of radio occultation measurements made with a receiver inside the Earth's atmosphere, Ann. Geophys., 20, 1253-1256, https://doi.org/10.5194/angeo-20-1253-2002, 2002.

Healy, S. and Thépaut, J. N.: Assimilation experiments with CHAMP GPS radio occultation measurements, Q. J. Roy. Meteorol. Soc., 132, 605-623, https://doi.org/10.1256/qj.04.182, 2006.

Healy, S. B.: Refractivity coefficients used in the assimilation of GPS radio occultation measurements, J. Geophys. Res., 116, D01106, https://doi.org/10.1029/2010JD014013, 2011.

Jensen, A. S., Lohmann, M. S., Benzon, H.-H., and Nielsen, A. S.: Full Spectrum Inversion of radio occultation signals, Radio Sci., 38, 1040, https://doi.org/10.1029/2002RS002763, 2003.

Jensen, A. S., Lohmann, M. S., Nielsen, A. S., and Benzon, H.-H.: Geometrical optics phase matching of radio occultation signals, 
Radio Sci., 39, RS3009, https://doi.org/10.1029/2003RS002899, 2004.

Kirchengast, G., Hafner, J., and Poetzi, W.: The CIRA86aQ_UoG model: An extension of the CIRA-86 monthly tables including humidity tables and a Fortran95 global moist air climatology model, IMG/UoG Techn. Rep. for ESA/ESTEC, 8, Eur. Space Agency, Paris, France, 1999.

Kursinski, E. R., Hajj, G. A., Hardy, K. R., Schofield, J. T., and Linfield, R.: Observing Earth's atmosphere with radio occultation measurements, J. Geophys. Res., 102, 23429-23465, 1997.

Lesne, O., Haase, J., Kirchengast, G., Ramsauer, J., and Poetzi, W.: Sensitivity Analysis of GNSS radio occultation for airborne sounding of the troposphere, Phys. Chem. Earth, 27, 291-299, 2002.

Lulich, T. D., Garrison, J. L., Haase, J. S., Yang, Y. M., Voo, J., Xie, F., and Muradyan, P.: Open loop tracking of radio occultation signals from an airborne platform, Proceedings of the 23rd International Technical Meeting of the Satellite Division of the Institute of Navigation, ION GNSS 2010, 21-24 September, Portland, OR, 2010.

Luntama, J.-P., Kirchengast, G., Borsche, M., Foelsche, U., Steiner, A., Healy, S., von Engeln, A., O'Clerigh, E., and Marquardt, C.: Prospects of the EPS GRAS mission for operational atmospheric applications, B. Am. Meteorol. Soc., 89, 1863-1875, https://doi.org/10.1175/2008BAMS2399.1, 2008.

Montgomery, M. T., Davis, C., Dunkerton, T., Wang, Z., Valden, C., Torn, R., Majumdar, S. J., Zhang, F., Smith, R. K., Bosart, L., Bell, M. M., Haase, J. S., Heymsfield, A., Jensen, J., Campos, T., and Boothe, M. A.: The Pre-Depression Investigation of Cloud systems in the Tropics (PREDICT) experiment: Scientific basis, new analysis tools, and some first results, B. Am. Meteorol. Soc., 92, 153-172, https://doi.org/10.1175/BAMS-D11-00046.1, 2012.

Muradyan, P.: GPS/INS navigation precision and its effect on airborne radio occultation, MS thesis, Purdue University, West Lafayette, Indiana, USA, 93 pp., 2009.

Muradyan, P.: Profiling the atmosphere with the airborne GPS radio occultation technique using open-loop tracking, $\mathrm{PhD}$ thesis, Purdue University, West Lafayette, Indiana, 196 pp., 2012.

Muradyan, P., Haase, J. S., Xie, F., Garrison, J. L., Lulich, T., and Voo, J.: GPS/INS navigation precision and its effect on airborne radio occultation retrieval accuracy, GPS Solutions, 15, 207-218, https://doi.org/10.1007/s10291-010-0183-7, 2010.

Murphy, B., Haase, J. S., Muradyan, P., Garrison, J. L., and Wang, K.-N.: Airborne GPS radio occultation refractivity profiles observed in tropical storm environments, J. Geophys. Res., 120, 1690-1709, https://doi.org/10.1002/2014JD022931, 2015.

Rocken, C., Anthes, R., Exner, M., Hunt, D., Sokolovskiy, S., Ware, R., Gorbunov, M., Schreiner, W., Feng, D., Herman, B., Kuo, Y.-H., and Zou, X.: Analysis and validation of GPS/MET data in the neutral atmosphere, J. Geophys. Res., 102, 29849-29866, https://doi.org/10.1029/97JD02400, 1997.
Smith, E. K. and Weintraub, S.: The constants in the equation for atmospheric refractive index at radio frequencies, Proc. Inst. Radio Eng., 41, 1035-1037, 1953.

Sokolovskiy, S., Rocken, C., Schreiner, W., and Hunt, D.: On the uncertainty of radio occultation inversions in the lower troposphere, J. Geophys. Res., 115, D22111, https://doi.org/10.1029/2010JD014058, 2010.

Sokolovskiy, S. V.: Effect of superrefraction on inversions of radio occultation signals in the lower troposphere, Radio Sci., 38, 1058, https://doi.org/10.1029/2002RS002728, 2003.

Voo, J. K., Garrison, J. L., Haase, J. S., and Lulich, T. D.: Recent experiments in ocean remote sensing with bistatic radar using global navigation satellite signals, in 2009 IEEE Radar Conference, Pasadena, Calif., IEEE, New York, p. 5, https://doi.org/10.1109/RADAR.2009.4977115, 2009.

Wang, K.-N., Garrison, J. L., Acikoz, U., Haase, J. S., Murphy, B. J., Muradyan, P., and Lulich, T.: Open-loop tracking of rising and setting GPS radio-occultation signals from an airborne platform: Signal model and error analysis, IEEE T. Geosci. Remote, 54, 3967-3984, https://doi.org/10.1109/TGRS.2016.2532346, 2016.

Wang, K.-N., Garrison, J. L., Haase, J. S., and Murphy, B. J.: Improvements to the GPS airborne radio occultation in the lower troposphere through implementation of the phase matching method, J. Geophys. Res., 122, 10266-10281, https://doi.org/10.1002/2017JD026568, 2017.

Ware, R., Rocken, C., Solheim, F., Exner, M., Schreiner, W., Anthes, R., Feng, D., Herman, B., Gorbunov, M., Sokolovskiy, S., Hardy, K., Kuo, Y., Zou, X., Trenberth, K., Meehan, T., Melbourne, W., and Businger, S.: GPS sounding of the Atmosphere from Low Earth Orbit, Preliminary Results, B. Am. Meteorol. Soc., 77, 19-40, https://doi.org/10.1175/15200477(1996)077<0019:GSOTAF>2.0.CO;2, 1996.

Xie, F., Syndergaard, S., Kursinski, E. R., and Herman, B. M.: An Approach for Retrieving Marine Boundary Layer Refractivity from GPS Occultation Data in the Presence of Super-refraction, J. Atmos. Ocean. Tech., 23, 1629-1644, 2006.

Xie, F., Haase, J. S., and Syndergaard, S.: Profiling the Atmosphere using the Airborne GPS Radio Occultation Technique: A Sensitivity Study, IEEE T. Geosci. Remote, 46, 3424-3435, https://doi.org/10.1109/TGRS.2008.2004713, 2008.

Xie, F., Wu, D. L., Ao, C. O., Kursinski, E. R., Mannucci, A., and Syndergaard, S.: Super-refraction effects on GPS radio occultation refractivity in marine boundary layers, Geophys. Res. Lett., 37, L11805, https://doi.org/10.1029/2010GL043299, 2010.

Yoshihara, T., Fujii, N., Saitoh, S., Sakai, T., Matsunaga, K., Hoshinoo, K., Tsuda, T., Aoyama, Y., and Danno, S.: Airbornebased downwardlooking GPS occultation experiments, IEICE Trans. Commun. JPN Eddition, J89-B(7), 1233-1241, 2006 (in Japanese).

Zuffada, C., Hajj, G. A., and Kursinski, E. R.: A novel approach to atmospheric profiling with a mountain-based or airborne receiver, J. Geophys. Res., 104, 24435-24447, https://doi.org/10.1029/1999JD900766, 1999. 